\title{
Dynamic Performance Analysis of Two Regional Nuclear Hybrid Energy Systems
}

\author{
Humberto E. Garcia, Jun Chen, Jong S. Kim, Richard B. Vilim, William R. Binder, \\ Shannon M. Bragg Sitton, Richard D. Boardman, Michael G. McKellar, Christiaan J. \\ J. Paredis
}

Idaho National Laboratory, 2525 N. Fremont Drive, Idaho Falls, Idaho, USA.

\begin{abstract}
In support of more efficient utilization of clean energy generation sources, including renewable and nuclear options, hybrid energy systems (HES) can be designed and operated as flexible energy resources (FER) to meet both electrical and thermal energy needs in the electric grid and industrial sectors. These conceptual systems could effectively and economically be utilized, for example, to manage the increasing levels of dynamic variability and uncertainty introduced by variable energy resources (VER) such as renewable sources (e.g., wind, solar), distributed energy resources, demand response schemes, and modern energy demands (e.g., electric vehicles) with their ever changing usage patterns. HES typically integrate multiple energy inputs (e.g., nuclear and renewable generation) and multiple energy outputs (e.g., electricity, gasoline, fresh water) using complementary energy conversion processes. This paper reports a dynamic analysis of two realistic HES including a nuclear reactor as the main baseload heat generator and to assess the local (e.g., HES owners) and system (e.g., the electric grid) benefits attainable by their application in scenarios with multiple commodity production and high renewable penetration. It is performed for regional cases - not generic examples - based on available resources, existing infrastructure, and markets within the selected regions. This study also briefly addresses the computational capabilities developed to conduct such analyses.
\end{abstract}

Keywords: Hybrid Energy Systems, Flexible Operation, Variable Renewable Generation, Ancillary Service

\section{Acronyms}

$\begin{array}{ll}\text { AHG } & \text { auxiliary heat generation } \\ \text { BOP } & \text { balance of plant } \\ \text { DME } & \text { dimethyl ether }\end{array}$

तु Corresponding Author: Humberto E. Garcia; email: humberto.garcia@inl.gov; Tel: +1 208526 7769; Fax: +1 2085263677

Preprint submitted to Energy

March 3, 2016 


\begin{tabular}{|c|c|}
\hline DNI & direct normal irradiance \\
\hline ESE & energy storage element \\
\hline $\mathrm{FCV}$ & flow control valve \\
\hline FER & flexible energy resource \\
\hline FGR & flexible generation resource \\
\hline FLR & flexible load resource \\
\hline FOM & figures of merit \\
\hline FWPP & fresh water production plant \\
\hline GHG & Greenhouse Gas \\
\hline GPP & Gasoline Production Plant \\
\hline HES & Hybrid Energy Systems \\
\hline ISO & Independent System Operator \\
\hline LPG & liquefied petroleum gas \\
\hline MSL & Modelica Standard Library \\
\hline MTG & methanol-to-gasoline \\
\hline NG & natural gas \\
\hline NHES & Nuclear Hybrid Energy Systems \\
\hline NSSS & Nuclear Steam Supply System \\
\hline $\mathrm{PCV}$ & pressure control valve \\
\hline PHG & primary heat generation \\
\hline PV & photovoltaic \\
\hline PWR & pressurized water reactor \\
\hline REN & Renewable \\
\hline $\mathrm{RO}$ & reverse osmosis \\
\hline RTO & Regional Transmission Organization \\
\hline TEC & thermal to electrical conversion \\
\hline VER & variable energy resource \\
\hline
\end{tabular}




\section{Introduction}

\subsection{Background}

Energy generation and utilization in the U.S. has historically exhibited one to one source use pairings [1]. Each major natural energy source is primarily used for one purpose; e.g., nuclear and coal for electricity, natural gas for heating (with a fraction going to electricity), and petroleum for transportation fuels. This constricted architecture may lead to undesired consequences or externalities if any one of these sources is disrupted. The upsets might also be in the uses of energy, for instance, if fuel cell and electrical vehicles or plug in hybrid vehicles running primarily on electricity become predominant. The consequences of these types of events can be social, economic, geopolitical, or environmental in nature.

Although expected to provide important benefits, it has been largely recognized that increasing renewable penetration and inclusion of time varying loads, such as electric vehicles, poses significant technical and economic challenges in terms of electric grid integration, stability, and modernization [2]. This is due to the unpredictability, nondispatchability, and high variability associated with renewable energy sources, such as wind and solar power, and the variability in modern loads. Although small levels of renewable penetration and variable loads have tolerable effects on grid operation, high levels may require significant changes in the traditional energy systems topology and grid infrastructure. In general, it may be more cost effective and less complex to attenuate the variability introduced by renewable energy and modern demands via both electrical and thermal means. This variability smoothing may be accomplished by using energy storage devices such as electric batteries and flywheel systems (e.g., [2, 3]), or by extending the architecture of traditional energy systems to enable multiple energy commodity exchanges, including dispatchable electricity, other energy storage products, such as hydrogen and chemicals, and basic products, such as fresh water. In addition to facilitating the incorporation of high levels of renewable penetration, it is equally important for energy solutions to be economically attractive while minimizing environmental impacts.

In order to increase the robustness, resiliency, adaptability, and flexibility of the U.S. and world energy network towards more effectively responding to resource costs and market drivers or conditions, a more flexible, distributed energy flow landscape and infrastructure is needed to combine various energy generation sources and multiple energy users. This leads to the notion of a HES: multiple energy inputs converted to multiple energy products using complementary energy conversion processes. By adding non-traditional energy sources, such as renewable generation, and non-electricity products, such as transportation fuels, energy system hybridization is a promising strategy to achieve energy security and resilience through diversification and integration of energy portfolios. In this manner, not only undesirable economic conditions but also environmental concerns can be resolved. In order to reduce pollution and dependence on fossil resources and to cost-effectively produce basis products such as fresh water, a coordinated energy strategy may aim to derive electricity from clean energy sources (e.g., nuclear and renewable energy) and to produce basis commodities and transportation fuels from regional carbon resources (e.g., natural gas, coal, and biomass). Higher levels of renewable energy penetration in the current energy portfolio are a desirable goal as a means of attaining improved resource utilization and environmental sustainability. Multiple efforts 
(e.g., [4-6]) have explored, to various degrees, the idea of closely combining multiple energy sources with diverse energy utilization paths. There are also examples of HES being proposed to act in a stand alone manner at off the grid locations. The selection of the particular Nuclear Hybrid Energy Systems (NHES) configurations studied herein, and the potential locations for their deployment (discussed in Sections 2.1.1 and 2.2.1), were motivated by the efforts and findings reported in [7], which set the foundation for the current regional studies. Small Modular Reactors (SMRs) are selected for the baseload generation system integrated within the selected NHES configurations due to their anticipated technical and economic advantages, including:

- Scalability;

- Incremental capital investment with phased installation;

- Complementary in energy output with renewable generators;

- Amenable to distributed energy solutions.

While the primary objective of this paper is to investigate the performance characteristics of two selected NHES configurations, the dynamic modeling, control, simulation, and optimization capabilities developed to support such dynamic analysis is also briefly discussed.

\subsection{Objective and Approach}

The goal herein is to evaluate the value proposition of HES that incorporate nuclear and renewable energy. The objective of this study is to analyze NHES that can:

- enable greater penetration of renewable energy in a cost effective manner, while providing energy for commodity production and grid services comparable to traditional electricity generation;

- support smooth integration of diverse energy sources and products within existing power and energy infrastructures, while also reducing greenhouse gas (GHG) emissions;

- change the manufacture and delivery of trade-able energy commodities (e.g., hydrogen, methanol, and ammonia);

- enhance the use of carbon resources for the production of chemical commodities (e.g., fertilizers and transportation fuel) and consumer products (e.g., textiles, polyethylene, and plastics);

- promote conversion of non-consumable resources, such as brackish, salty, and waste water, to essential commodities, such as fresh water;

- provide an approach to produce and deliver energy that is constrained by local markets, geography, water availability, and transportation/delivery systems;

- improve the thermodynamic efficiency and work productivity through coordinated dynamic control of energy conversion systems;

- enhance both power and energy quality and management, in addition to improving reliability, security, and value optimization;

- provide sustainable energy security. 


\subsection{Proposed methodology}

In order to effectively design, evaluate, operate, and optimize multi-domain energy system solutions, innovative physical and computational capabilities are needed so that prototype demonstration and eventual deployment are successfully achieved at minimum cost and risk. Given the intrinsic dynamic nature of the energy resources involved, the design, control, analysis, and optimization of these energy solutions should be conducted within a dynamic setting. To this end, this paper also briefly reviews the gaps between the existing and novel capabilities needed to develop these modern energy solutions and to achieve the anticipated benefits. In the graded, multi-layer hierarchical approach envisioned, analysis efforts are expected to initially encompass the exploratory technical assessment of multiple HES alternatives via the use of computational capabilities (such as models and co-simulations) to then be progressively integrated with real-time capabilities and actual physical hardware in hardware-in-the-loop (HiL) demonstrations.

Figure 1 partially illustrates the guiding analytical framework employed in this study. In particular, technical and economic design criteria and figures-of-merit (FOM) are identified to characterize, quantify, and compare key performance metrics for NHES alternatives. These FOM are used to optimize the design (e.g., component types and sizes) and the operations (e.g., optimal mixture of commodity production) of NHES alternatives. In conducting these optimization activities, modeling, control, and co-simulation capabilities, with appropriate levels of granularity and accuracy, are used to estimate system performance. Thus, a number of computational capabilities (denoted by $\mathrm{C} \#$ in Figure 1) and physical assets (denoted by P\# in Figure 1) emulating HES alternatives are accordingly integrated and co-simulated to compute their performance characteristics and limitations. Quantification of selected FOM can be repeated iteratively to refine system design and operation. Figure 1 also illustrates the possibility of initially utilizing only computational $\mathrm{C \#}$ assets (e.g., models), as in the present study, then progressively moving to experimental ensembles consisting of both computational $\mathrm{C \#}$ and physical $\mathrm{P} \#$ (e.g., hardware) assets integrated within non-real-time and real-time environments.

The implications of variability and uncertainty in the time varying renewable energy generation and electricity demand can only be effectively understood in a dynamic setting. Hence, the current work adopts dynamic performance analysis to characterize tightly coupled HES. A flexible dynamic modeling and simulation (M\&S), control, and optimization capability was developed to integrate and control component models. This paper addresses only a portion of the computational capabilities employed in this study; namely, the technical components, the modeling, control, and co-simulation components, and the figures of merit (FOM) quantification components. Figure 2 illustrates the dynamic M\&S, control, and optimization capability developed. This analytical tool was utilized to explore the operational flexibility of the two NHES configurations considered under different scenarios in order to better understand their dynamic properties and key potentials. Simulation results are quantitatively analyzed in light of selected FOM, including operational requirements to participate in the regulatory and/or wholesale electricity market services.

Inputs to the dynamic computational analysis tool include: grid service needs; renewable generation profiles (e.g., wind, solar photovoltaic PV); relevant time dependent commodity prices (e.g., electricity, gasoline, fresh water); and relevant time dependent feedstock prices (e.g., natural gas, water). Given these inputs to the integrated component models, an HES configuration can then be analyzed under two distinct modes. First, 


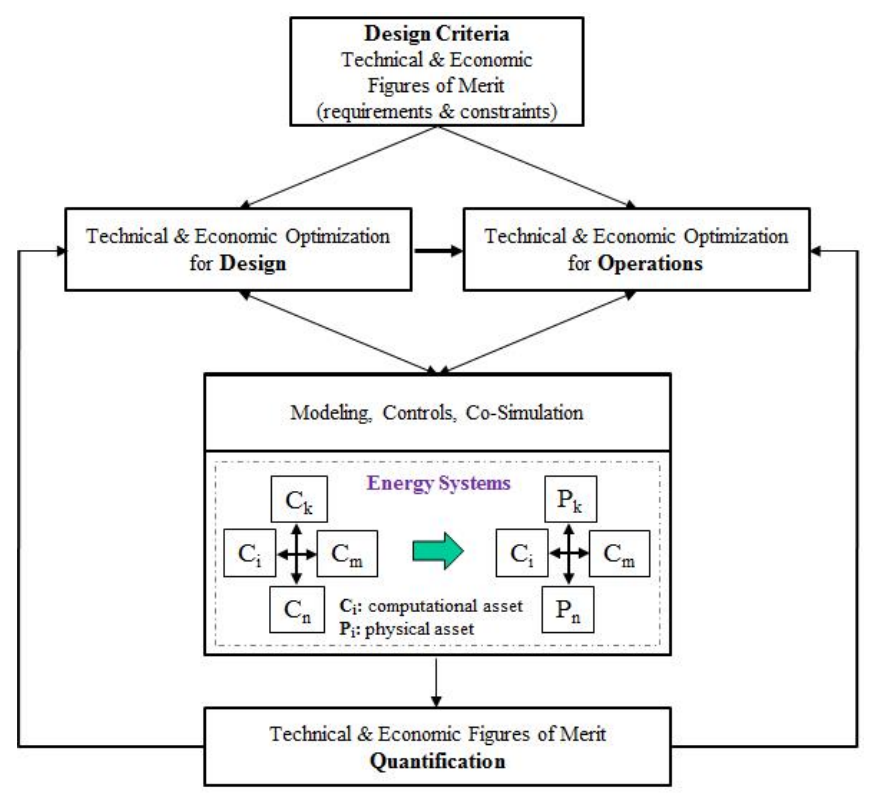

Figure 1: High level diagram conveying the design, control, analysis, and optimization framework for HES.

when analyzing its participation in the ancillary service market, the HES is operated in a manner in which the electric grid requirements are satisfied as a priority. Second, when analyzing its participation in the commodity sale market, the HES is operated (as determined by an operations optimizer) to support the economic optimization of the system. In the latter case, the goal is to optimize a given (economic) objective value. Time series of numerous variables are then computed, including emissions, commodity production, and feedstock consumption, and utilized to quantify the selected FOM.

The Modelica modeling language is used with Dymola [8] as the M\&S environment to construct and simulate the dynamic models of the selected NHES. The level of modeling detail varies from mapping functions to more detailed models (i.e., representative physics-based modeling). In-house developed packages and open source libraries were utilized to facilitate M\&S. In particular, the Modelica Standard Library (MSL) version 3.2.1 and ThermoPower version 2.1 are utilized. Modelica models were implemented using the commercially available Modelica language software Dymola, version 2015. The computational models introduced in this paper were developed at a level of granularity and accuracy adequate for conducting reliability studies.

It is important to point out that, except for equations describing renewable energy generation, this manuscript does not include the specific physical and mathematical formulations that characterize each component modeled due to page length limitations. In particular, each HES arrangement under consideration is modeled as a detailed dynamical model, which integrates over seven hundred (700) components, each incorporating its own particular parameters and mathematical equations describing its performance; when put together, over twenty six hundreds (2600) and thirty three hundreds (3300) 


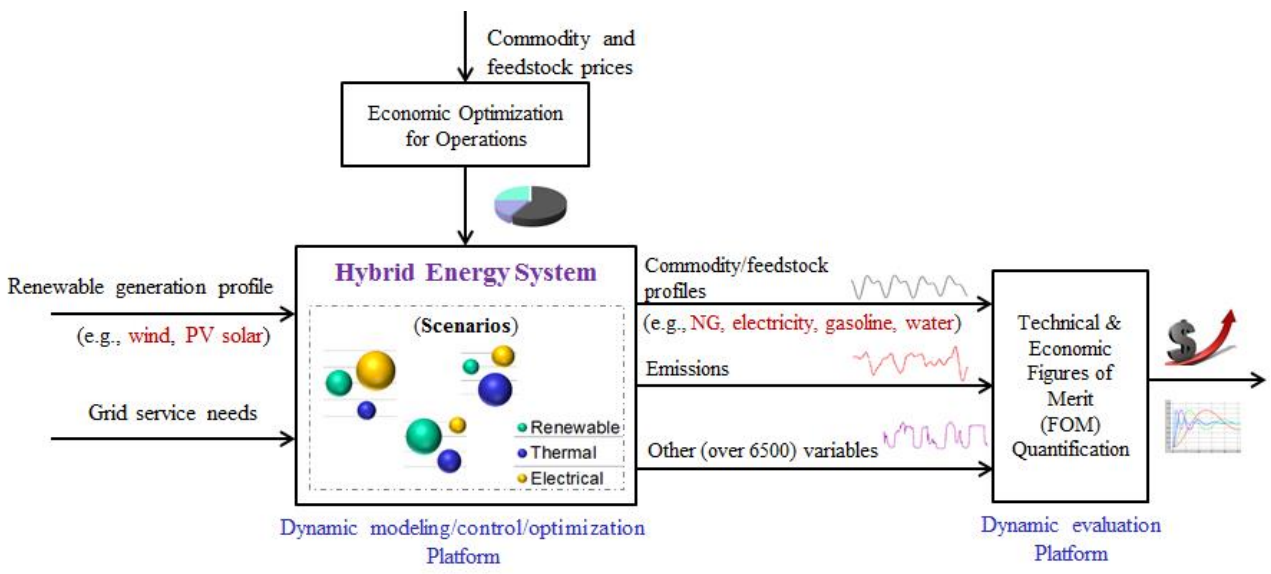

Figure 2: High level diagram of developed analysis capability.

equations are simulated. These models characterize a large range of components, from single components such as valves, pipes, vessels, drums, pumps, turbines, and single-loop controllers, to aggregated ones such as heat exchangers, headers, condensers, boilers, reverse osmosis units, nuclear systems, power cycles, and multi-loop supervisors. These integrated models of HES arrangements allow the tracking of more than sixty five hundreds (6500) variables as indicated in Fig. 2. Furthermore, the HES arrangements here considered are conceptual formulations and do not emulate any existing industrial installation. Consequently, simulation results were not validated against measurements collected from real industrial processes. Instead, simulation results were partially verified against data available in the literature or by experts in the field. Furthermore, models used in the reported simulations are derived from models included in the MSL and other Modelica-based libraries, which are subjected to rigourous verification procedures by their authors and the Modelica User Association before their release. For a detailed description of the governing equations utilized in the reported analysis, the readers are referred to [9], where the physical and mathematical models as well as main parameters and input/output variables used for the desalination process, for example, are presented and discussed in detail.

\subsection{Manuscript organization}

The rest of this paper is organized as follows. Section 2 briefly introduces the topological architecture of considered HES configurations. In Section 3, the methodology utilized to conduct dynamic performance analyses is discussed, including FOM, test plan, and renewable and demand assumptions and simulations. In Section 4, dynamic performance analysis results are presented and their implications are discussed. Section 5 concludes this paper. 


\section{NHES Configurations}

The NHES configurations considered in this paper include energy components typically utilized for producing electricity and several operations yielding multiple forms of energy commodities besides electricity. Specifically, two different NHES configurations are considered. The first configuration, referred to as NHES_Texas, includes a flexible thermal load. This configuration employs a nuclear plant and a series of wind turbines to produce electricity and convert carbon resources to gasoline using excess thermal capacity. The second configuration, referred to as NHES_Arizona, includes a flexible electrical load. This configuration employs a nuclear plant and solar PV stations for energy generation, and yields electricity to meet grid demand and to produce fresh water using excess electrical capacity. In both cases, the NHES is connected to the electric grid at a point of common coupling. This section briefly describes the detailed configurations and their dynamic modeling and simulation. The important phenomena for accurate simulation of their dynamic behavior are characterized in these models. As mentioned in the introduction, this paper does not describe, in detail, the specific governing equations included in each model. Details are briefly presented via summary descriptions of key models and screen captures to illustrate the selected configurations.

\subsection{NHES for West Texas with a Flexible Thermal Load}

NHES_Texas can be operated as a flexible generation resource (FGR) via flexible use of generated thermal energy.

\subsubsection{Location}

This case study was developed based on options considered in [7]. A primary goal of the Texas case study is to utilize the states large oil and gas industry and wind capacity. The selected process application refines natural gas into gasoline for transportation. Since 2001, wind generation in Texas has increased nearly $1200 \%$, reaching a wind capacity of over $12 \mathrm{GW}$ in 2013. This is approximately one fifth of the total wind capacity in the United States, making Texas the largest producer of wind energy [10,11]. Texas is also the United States largest crude oil producing state, producing just over one third of total crude oil production in 2013, and the largest natural gas producing state, producing just under one third of total natural gas production in 2013 [12, 13].

Selecting an attractive location for an integrated nuclear renewable HES is nearly as important as selecting its marketable product to ensure profitability and usefulness to society. While a location must be both amenable to the selected renewable generation and to marketing co-products, it must also be able to deliver the electricity generated without significant modification to available infrastructure. In Texas, it is possible to sell electricity to either the Eastern Interconnection or to Electricity Reliability Council of Texas (ERCOT) Interconnection depending on the specific location in the state. Three Texas locations were considered for this study; namely, the Permian Basin of West Texas, the area near the city of Abilene, and the Texas panhandle. The Permian Basin of West Texas has the highest concentration of oil wells in Texas. Oil wells, in addition to producing oil, also produce natural gas, albeit at levels that are not profitable to sell to market. Although venting and flaring of natural gas is the preferred practice, regulations require producers to capture natural gas for environmental reasons [14]. During 2013, an average of 62 million cubic feet per day of natural gas was vented in the Permian Basin 
[15], which could provide 8,000 barrels of liquid fuel. A typical natural gas to liquid fuel plant requires 290 million cubic feet per day of natural gas [16]. Five of the largest wind farms in the world are found in the area near the City of Abilene [17]. However, oil wells are scarcer than in the Permian Basin. The Texas panhandle location contains natural gas wells and has adequate average wind speed [18]. Considering the carbon resource of interest to the gas to liquids plant, natural gas, the availability of renewable wind energy, and the available electric interconnections, the panhandle location was chosen for the initial Texas case study. The close proximity of natural gas wells can provide the needed carbon source for the liquid fuel and the wind speeds are sufficient to use existing or to build additional wind farms for the hybrid system. In this location, the electricity would likely be sold to the Southwest Power Pool (SPP) of the Eastern Interconnection.

\subsubsection{Equipment layout}

Figure 3 shows a high-level process diagram of NHES_Texas, which include:

- 600 MWt heat generation plant, denoted as primary heat generation (PHG), consisting of an SMR and a steam generator that provides steam for both electricity generation and for gasoline production. The balance of plant (BOP) is modeled as follows:

- A set of three steam turbines on a single shaft, paired with an electric generator that converts steam into electricity; denoted as thermal to electrical conversion (TEC),

- renewable power generation source consisting of a series of wind turbines, with total wind plant capability of up to $45 \mathrm{MWe}$, denoted as REN (renewable). This renewable power generation capacity was selected to accordingly correspond to the nominal capacity chosen for the gasoline production plant (GPP). Greater levels of renewable integration is possible,

- electrical storage (i.e., a system scale battery set) used for power smoothing of the electricity generated by the renewable source; denoted as energy storage element (ESE),

- secondary boiler that transfers heat produced by the SMR to the GPP, located approximately $1 \mathrm{~km}$ from the SMR site,

- auxiliary heat generation (AHG) plant (i.e., a NG fired steam generator boiler plant) of up to 150 MWt capacity that generates additional on demand steam,

- heat distribution header that distributes process steam to various locations of GPP,

- chemical plant complex able to utilize up to $150 \mathrm{MWt}$ and convert NG and water into gasoline (and liquefied petroleum gas [LPG]) at GPP,

- sufficient carbon resources (e.g., NG) to support chemical production of gasoline,

- electric grid connected to NHES_Texas at a point of common coupling and consuming electricity up to 180 MWe.

As shown in Figure 3, there are two steam cycles. For thermal energy conversion and transfer, the process steam coming out of the steam generator is modulated (by a pressure control valve [PCV]) for distribution into two locations: one for use by the power cycle to generate electricity and the other for use by the secondary boiler to transfer thermal energy to the GPP. The process steam through the power cycle and the path through the secondary boiler are merged together, after being condensed into water, utilized as feedwater to the steam generator. Each steam flow rate is controlled by a corresponding 


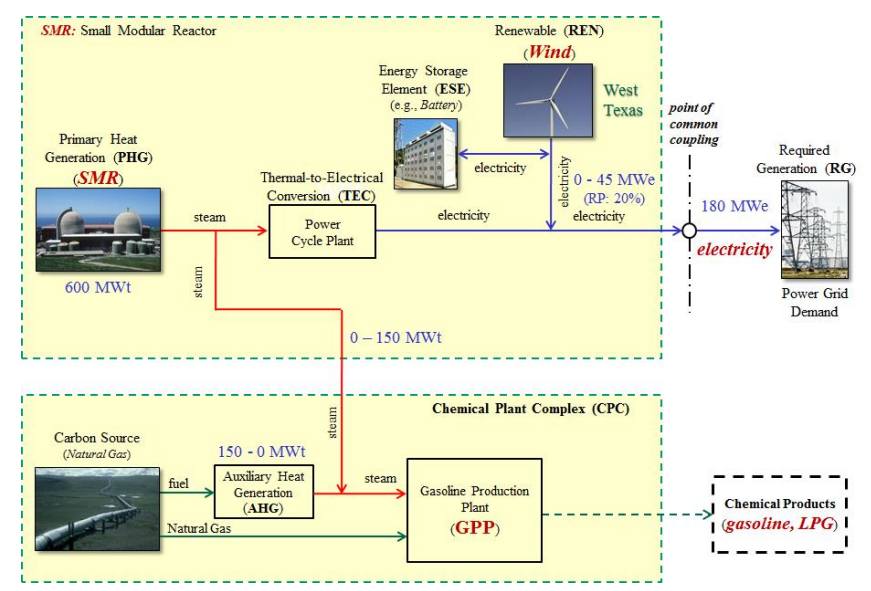

Figure 3: Network topology of NHES_Texas with a flexible thermal load.

main pump to maintain the required quality of superheated steam coming out of the steam generator. This path forms the first steam cycle in which the water flow mass is preserved. The second steam cycle is formed by the steam going through GPP and that generated by the secondary boiler. However, as steam is consumed for gasoline production, makeup water enters this water system.

\subsubsection{Components}

PHG is the primary source of energy for NHES_Texas, which transfers heat to the feedwater coming from the BOP. The outflow of the steam generator (i.e., superheated steam) is then delivered to:

1. Power cycle to produce additional electricity for meeting grid demand, after considering the contribution received from renewable sources;

2. GPP for synthesizing gasoline from natural gas.

As suggested in [4-6], the strategy for efficient energy utilization is to build the nuclear reactor with a capacity that meets the peak electrical load, with the remaining process steam accordingly diverted to the production of chemicals or other products. In this paper, the nuclear reactor is sized for and operated at its nominal capacity, i.e., 600 MWt. The thermal to electrical conversion (TEC) system is a Rankine power cycle and the primary source of electricity in NHES_Texas.

NHES_Texas is operated in a manner such that the electricity produced by the power cycle and the wind turbines is managed by a supervisory controller and distributed to the electric grid according to its needs or to an optimal electric generation strategy decided by an operations optimizer (supporting online economic operations optimization, see [19]) based on multiple factors including market price of each product. Because their fuel is free, renewable sources of energy are typically held at maximum available output and are not required to operate at lower than maximum output as this otherwise would not be cost effective for renewable generation plants under current energy market rules. Therefore, renewable energy is treated in this study as a must take input (i.e., 
no renewable curtailment). This renewable generation is usually characterized by high variability, intermittency, and non-dispatchability. Consequently, as shown in Figure 3 , it is introduced via an electric battery performing power smoothing, thus partially mitigating the renewables high variability. The effect of this power smoothing action is similar to a low pass filter. The degree of variability removal (or degree of smoothing) can be characterized by a smoothing time constant. The smoothing time constant in turn defines the following two characteristics of the battery:

1. charge/discharge power provided by the battery to either discharge or accept charge,

2. charge/discharge storage (capacity) representing the total amount of energy during a single charge or discharge period.

In particular, a bigger time constant translates into a larger charge/discharge power and capacity specification for the battery. Therefore, a battery with larger charge/discharge power and capacity can in general achieve a higher degree of smoothing (or variability attenuation). Although there are many other candidates for ESE, such as compressed air energy storage and flywheel, a grid scale electric battery is assumed in this study.

The GPP consists of the following unit operations:

- steam reforming plant utilizing steam to convert natural gas into syngas;

- methanol synthesis and purification plant producing methanol;

- methanol storage container, and

- methanol-to-gasoline (MTG) conversion plant requiring thermal energy from steam and outputting gasoline (and a small fraction of LPG).

The GPP utilizes process steam produced by the PHG (and possibly complemented with steam generated by auxiliary heat generation [AHG]) as shown in Figure 3 to convert carbonaceous fuels (natural gas) into chemical products (gasoline and LPG). The (auxiliary heat generation) AHG system is a natural gas (NG) fired boiler and generates steam solely for the GPP to meet its steam demand if the steam coming from the PHG is not sufficient to maintain the desired constant gasoline production level. By generating additional steam to compensate for variability in the steam coming from PHG, AHG enables GPP to operate at a given constant production mode even under variability of renewable generation and grid demand. The sources of carbon and hydrogen to support GPP operations are assumed to be sufficiently large to support the required gasoline production goal. NHES_Texas is connected to the electric grid via a point of common coupling. The electricity generation profile that must be delivered to the electric grid by NHES_Texas is typically assigned by an Independent System Operator (ISO) or a Regional Transmission Organization (RTO). In general, ISO/RTO may solicit a time varying generation profile, according to the net-load variation and the market price fluctuation. The inherent assumption is that the PHG can generate sufficient energy to meet the required generation profile.

\subsubsection{Controls}

Numerous feedback controllers are augmented as low level controllers to maintain the desired process conditions, such as temperature, pressure, and mass flow rates at various locations in the given NHES. The temperature of the superheated steam coming out of 
the steam generator is controlled by two variable speed control pumps, which maintain the temperature at approximately $311.4{ }^{\circ} \mathrm{C}$, a set point calculated by considering the thermal power efficiency as well as the operational conditions of the steam turbines in the power cycle. The pressure in the power cycle is controlled by a PCV, which regulates the steam flow diverted to the secondary boiler. The flow into the steam turbines is, in turn, controlled by three flow control valves (FCV), one valve for each steam turbine. The FCVs are simultaneously regulated by a governor responsible for maintaining the speed of the turbine shaft at the specified equivalent $60 \mathrm{~Hz}$ demanded by the electric grid. These three FCV work accordingly to guarantee that the power cycle generates the exact amount of electricity as needed by the electric grid. The steam going through the steam turbines and the steam going through the secondary boiler are merged together, after they are condensed into water, which is then heated to $215.6{ }^{\circ} \mathrm{C}$ before feeding it into the steam generator. This is accomplished by a heat exchanger being regulated by a temperature control valve.

The conditions of the other steam cycle are also controlled by multiple flow, pressure, and level control valves. It is worth noting that, due to the variability of the renewable generation, the thermal energy sent to GPP is also subject to high variability. In order for GPP to operate at constant production, supplemental steam is provided by an AHG, whose operation is controlled by a PCV. This PCV is present to make sure that the steam flow resulting from combining the steam flow from the secondary boiler and the steam flow produced by AHG is provided to GPP at a constant pressure, which in turn guarantees the constant thermal energy needed by GPP to operate at full mode.

\subsubsection{Operations}

There are two units for electricity generation in NHES_Texas, namely, TEC and REN. Under supervisory control, these two electricity generation units are operated accordingly to deliver the electricity generation requested by the electric grid operator (e.g., an ISO, RTO) or by the operations optimizer (supporting online economic operations optimization, see [19]). In either case, the power delivered to the electric grid is assumed to be less than or equal to 180 MWe. This electricity production is the first output of NHES_Texas. The second output is chemical products (i.e., gasoline), which is produced from carbon sources (i.e., NG), steam generated by the PHG and, if needed, AHG. Note that the SMR is sized for full load operation (i.e., $600 \mathrm{MWt}$ ); therefore, it is capable of generating (without renewable contribution) sufficient process steam to meet the maximum electric grid demand of 180 MWe.

Under the extreme situation that the requested electricity generation is $180 \mathrm{MWe}$ and no renewable contribution is present, a small amount of steam (i.e., $9.67 \mathrm{~kg} / \mathrm{s}$ ) generated by the steam generator is still directed to the GPP, with the remaining majority of the steam duty being met by AHG. If the steam coming from the PHG is not sufficient to maintain the desired gasoline production goal, AHG is accordingly regulated to provide the required additional steam. By enabling the GPP to utilize steam generated from the PHG, NHES_Texas provides additional opportunities for flexible energy management, for providing various types of ancillary services, such as operating reserves (e.g., regulating, ramping, load following, and supplemental reserves), and for enabling operational flexibility for value (technical and/or economic) optimization. However, $\mathrm{CO}_{2}$ production in NHES_Texas varies accordingly with changes in net load (i.e. demand minus renewable 
generation) as steam production at AHG would vary in order to support constant GPP operation.

In order to provide ancillary service, NHES_Texas can increase or decrease electricity production when requested. For example, if the electricity production is $170 \mathrm{MWe}$ at a given time with 10 MWe coming from the wind turbines, then NHES_Texas can potentially increase or decrease its electricity production to as high as $190 \mathrm{MWe}$ or as low as $145 \mathrm{MWe}$, respectively. In the first case, GPP would be solely supported by AHG, while in the second case no steam is needed from AHG. Assuming a 10 MWe constant wind contribution, NHES_Texas can accept a change of 45 MWe (or more if an additional GPP is installed or the power setpoint for the SMR is accordingly reduced) in its electricity production this operating capacity is large enough to bid into the ancillary service market. Furthermore, since AHG is utilized to compensate the thermal energy supplied to GPP, NHES_Texas can maintain a given change in its electrical production for large time periods.

\subsubsection{Dynamic models}

Figure 4 shows the top level model for NHES_Texas. As seen from this screen capture, nineteen main subsystems can be identified as follows:

1. Physical Devices: Nuclear SMR, feedwater heater and thermal distribution center, power generation, secondary boiler, thermal conditioning, thermal transmission lines, auxiliary NG fired boiler, header network, auxiliary steam turbine generator, GPP, wind generation, battery-based power smoothing, electric grid

2. Control Devices: Main pumps supervisor, governor, power cycle supervisor, many low level controllers (embedded within corresponding subsystems, not shown), control bus

3. Evaluation Module: System evaluation (used to facilitate ease evaluation of multiple scenarios)

In order to provide a brief description of two of the subsystems implemented for NHES_Texas, Figure 5 shows the top level model for the GPP.

Before entering a steam methane reformer, the natural gas is compressed, heated, saturated with hot water, and mixed with a small amount of hydrogen. Subsequently, sulfur is removed from the gas and mixed with process steam to achieve the desired steam to carbon ratio. The natural gas/steam mixture is fed to a steam methane reformer consisting of primary steam reforming followed by secondary autothermal reforming, where syngas ( $\mathrm{CO}$ and $\mathrm{H} 2$ ) is produced. The syngas is fed to a methanol synthesis reactor, from which methanol is produced. Methanol product is purified in a distillation column to remove light gases prior to storage in the methanol intermediate product tank. This storage tank has a capacity of 24-48 hours of design flow and is held at about $50 \%$ full to allow it to compensate for 12-24 hours of high or low flow imbalance. Finally, methanol is converted to gasoline using ExxonMobils patented process. First, methanol is exothermically converted to an equilibrium concentration of dimethyl ether (DME), water, and methanol in the DME reactor. Next, the product of this reactor is mixed with recycle gas to cool the stream before it is introduced to the ZSM 5 catalytic MTG reactor. In this reactor, methanol and DME are converted to hydrocarbons ranging from methane to 1-naphtha. 


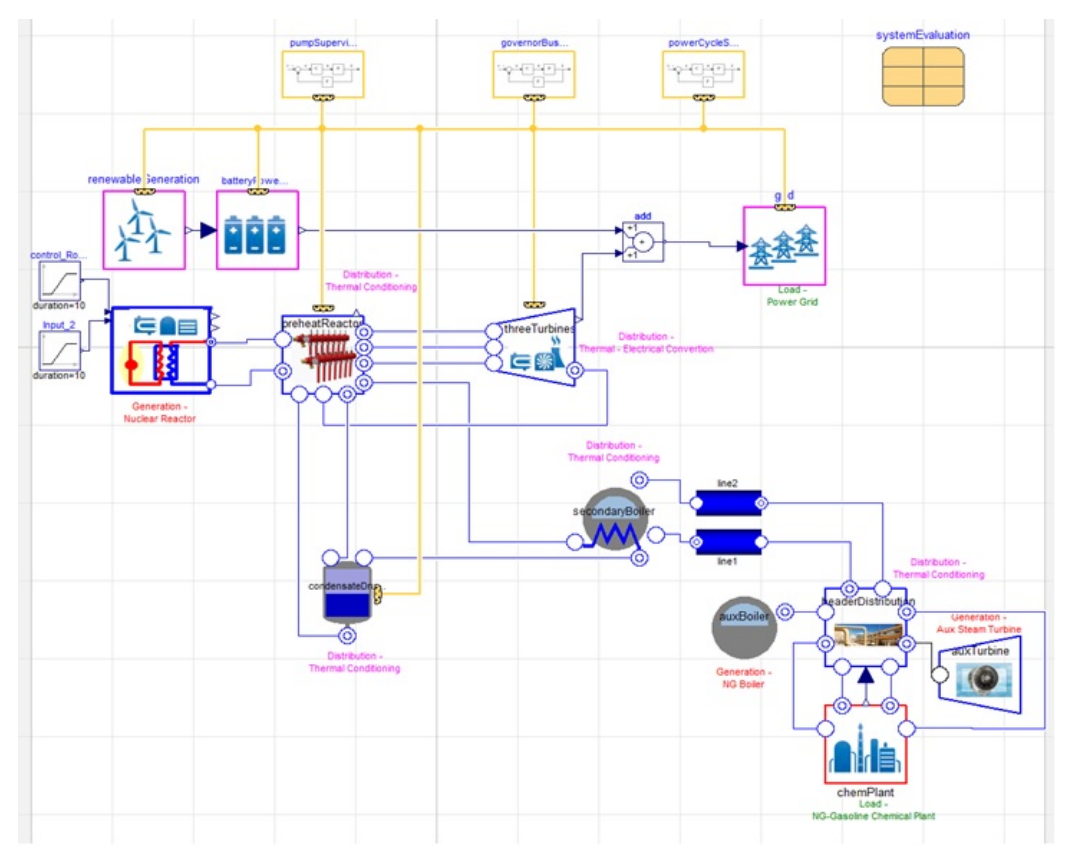

Figure 4: Top level model for NHES_Texas in Modelica.

The overall reaction from DME and MTG is exothermic, so the crude gasoline product is cooled via recuperation and by raising steam, followed by condensation. Finally, crude liquid gasoline is purified using several distillation columns (de-ethanizer, de-propanizer, and de-waxing), resulting in the final gasoline product as well as LPG product [16]. Detailed governing equations and models of these processes were initially developed and analyzed using ASPEN and then simplified formulations were implemented in Modelica.

As another example of the dynamic models developed, Figure 6 shows the top level model for the nuclear SMR used in both NHES_Texas and NHES_Arizona. In particular, the developed nuclear steam supply system (NSSS) provides on demand steam to multiple energy conversion processes that produce commodities for regional markets. The NSSS is based on pressurized water reactor (PWR) technology, which is regarded as commercially mature. The steam conditions are typical of a PWR with a temperature of $320{ }^{\circ} \mathrm{C}$ and a pressure of $7.0 \mathrm{MPa}$. The plant is representative in size and design of a small modular reactor (SMR). The NSSS includes the reactor, primary system, and steam generator. It couples to the BOP at the main steam line and the feed water inlet line. The NSSS is of an integrated design, where the primary system components are all located within the primary vessel. The primary coolant enters the reactor core where it is heated. It exits the core and flows up a riser to the reactor coolant pumps where it then reverses direction and flows down through the shell side of a once-through steam generator before returning to the core inlet. The pressurizer is located at the top of the riser. Subcooled feed water enters the tube side of the steam generator and rises up the tubes where heat is transferred from the shell side primary coolant. The secondary coolant exits the tubes 


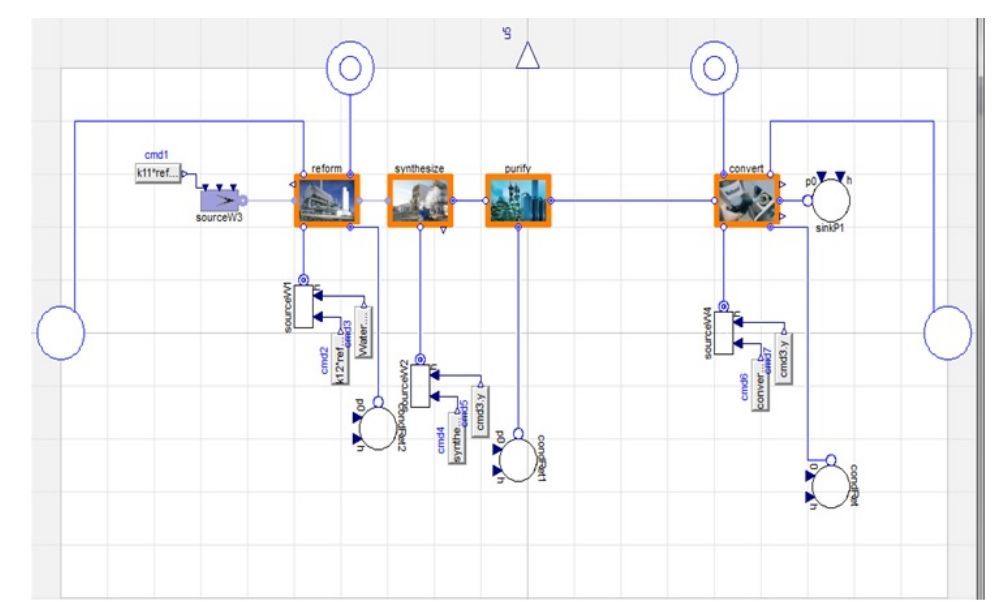

Figure 5: Top level model for gasoline production plant (GPP) used in NHES_Texas in Modelica.

Table 1: Full power conditions for pressurized water nuclear small modular reactor.

\begin{tabular}{|c|c|c|c|c|}
\hline $\begin{array}{c}\text { Reactor Nominal } \\
\text { Power }[\mathrm{MWt}]\end{array}$ & $\begin{array}{c}\text { Primary Loop } \\
\text { Flowrate }[\mathrm{kg} / \mathrm{s}]\end{array}$ & $\begin{array}{c}\text { Primary Loop } \\
\text { Pressure }[\mathrm{bar}]\end{array}$ & $\begin{array}{c}\text { Reactor Coolant } \\
T_{\text {out }}\left[{ }^{\circ} \mathrm{C}\right]\end{array}$ & $\begin{array}{c}\text { Reactor Coolant } \\
T_{\text {in }}\left[{ }^{\circ} \mathrm{C}\right]\end{array}$ \\
\hline 600 & 4500 & 140.7 & 319.8 & 296.8 \\
\hline $\begin{array}{c}\text { Steam } T_{\text {out }} \\
{\left[{ }^{\circ} \mathrm{C}\right]}\end{array}$ & Feedwater $T_{\text {in }}$ & Steam Outlet & Feedwater Inlet & Feedwater Mass \\
\hline$\left[{ }^{\circ} \mathrm{C}\right]$ & Pressure $[\mathrm{MPa}]$ & Pressure $[\mathrm{MPa}]$ & Flowrate $[\mathrm{kg} / \mathrm{s}]$ \\
\hline 311.5 & 215.6 & 6.8 & 7.1 & 304.4 \\
\hline
\end{tabular}

as superheated vapor. The values of process variables at full power are given in Table 1.

The NSSS is modeled in Modelica with the main phenomena governing plant behavior during normal steam production represented. A high-level rendering of the model is shown in Figure 7. The thermal hydraulic behavior of the core is represented by a single average fuel pin and its associated coolant channel. The fuel pin axial power profile is assumed to be uniform. The fuel pin is divided into ten axial nodes and the fuel pellet into three radial nodes. The energy equations for the fuel pin are solved for temperatures. The coolant channel is assembled from the water tube element in the ThermoPower library. An extension is created to link it to the cladding exterior temperature. The core neutronics is driven by reactivity that is communicated to the core through changes in reactor inlet temperature, reactor coolant mass flow rate, and control rod position. The main temperature reactivity feedbacks are temperature dependent coolant moderation and fuel Doppler. These are represented through temperature coefficients of reactivity. Unlike the case for liquid metal and gas reactors, structural feedbacks such as control rod thermal expansion are not significant since the average temperature of the core is near constant and the core full power temperature rise is less than $50{ }^{\circ} \mathrm{C}$. Structural feedbacks can therefore be neglected. The once-through steam generator is marked on 


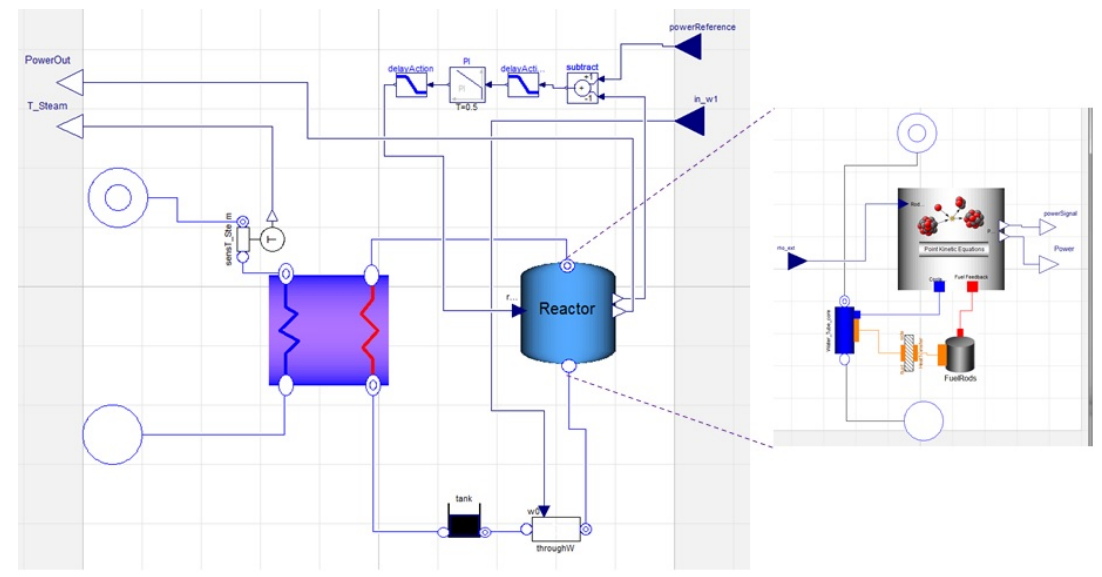

Figure 6: Top level model for the nuclear reactor used in NHES_Texas, NHES_Arizona in Modelica.

the secondary side by three heat different transfer regimes (subcooled, nucleate boiling, and superheat) and by a relatively small coolant inventory, from an energy capacitance standpoint. As this component is the interface between the main energy source, the reactor, and other HES sinks, it is important that its thermal hydraulic phenomena be well represented. It is also important that dynamic effects in the steam generator (mass and energy storage) are adequately modeled since the instantaneous heat rate is closely linked to the relative lengths of the heat transfer regimes and that these lengths can change quickly given the small energy capacitance.

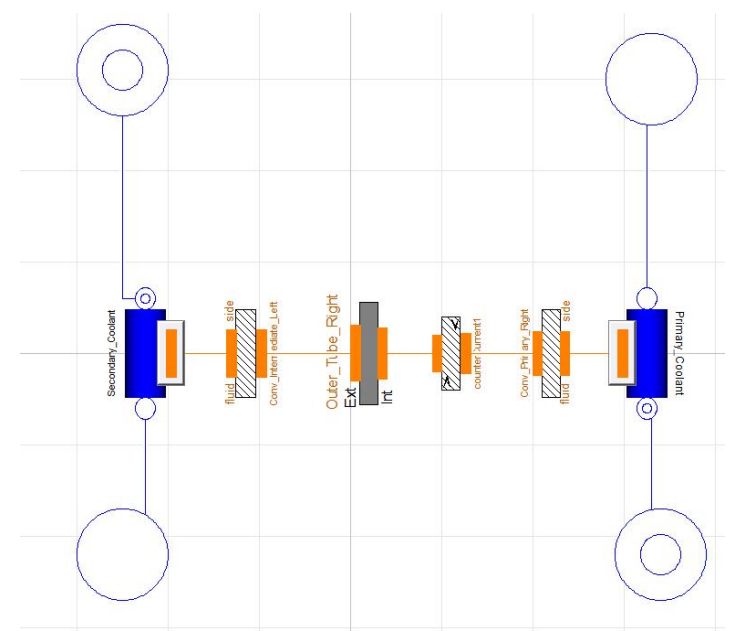

Figure 7: Model of the once-through steam generator in Modelica.

The reactor control system operates to control reactor thermal power by adjusting control rod reactivity. The controller compares measured reactor power to a user-supplied 
set point power to generate an error signal for input to a controller. The controller outputs control rod reactivity that drives the error in power to zero over time.

\subsection{NHES for Northeastern Arizona with a Flexible Electrical Load}

NHES_Arizona can be operated as a both FGR and flexible load resource (FLR).

\subsubsection{Location}

This case study was developed based on options considered in [7]. The specific location in northeast Arizona for this system was determined by consulting with the Arizona Governors Office of Energy Policy and the Arizona Collaboratory for Advanced Energy Solutions.

Arizona is expecting increased power and water needs over the next 15 to 20 years. The Arizona Public Service, the largest electric utility in Arizona, projects their peak power requirement to increase from 8,124 MWe in 2014 to 12,982 MWe by 2029. The renewable component of the Arizona energy mix is anticipated to increase from 3,182 GW-hr in 2014 to 6,944 GW-hr by 2029 [20]. Estimated population growth in Arizona is expected to be 10.5, 13.3 and 18.3 million people for the years 2035, 2060, and 2110, respectively. The annual water demands are projected to grow from the 2014 volume of 6.9 million acre-feet to between 8.2 and 8.6 million acre-feet in 2035; between 8.6 and 9.1 million acre-feet in 2060, and between 9.9 and 10.5 million acre-feet in 2110 [21]. Nine gigawatts of power is currently provided by coal fired plants in the northeast corner of the state. Fifty percent of those coal fired plants are predicted to be retired by 2020 due to EPA emission regulations $[16,22]$ and/or regional power generation preferences.

An integrated nuclear renewable HES could certainly benefit the northeast corner of Arizona. While other suitable locations for the NHES Arizona configuration may be identified within Arizona and elsewhere, a NHES solution could replace the coal fired power plant on the Navajo reservation in the northeast corner of the state, enabling it to use existing high voltage lines to transport electricity within Arizona and to California. The plant also sits above an aquifer that contains brackish water. By using a reverse osmosis (RO) desalination plant, potable water can be produced for use on the reservation and/or piped to other areas within Arizona, New Mexico, Colorado, and Utah. The selected NHES could aid the penetration of additional renewable energy by diverting power to desalinate brackish water in the area during times of excess power production.

Likewise, solar power plants are the largest renewable resource in Arizona, with the plants located primarily in the southwest corner of the state due to higher solar radiation and high population density. The aquifer in the northeast side of the state contains 250 million acre-feet of brackish ground water. This aquifer could potentially provide up to 180 million acre-feet of fresh water. For this study, a 600 MWt PWR and a 45 MWe reverse osmosis desalination plant are assumed to be constructed in the northeast region of Arizona. The selected renewable energy source is solar PV power co-located near the nuclear power plant. The RO desalination plant can fluctuate between 15 to 45 MWe to enable the penetration of the same amount of solar energy. This will produce 22,425 to $56,377 \mathrm{~m}^{3} / \mathrm{hr}$ of water, which provides the daily water needs for 0.95 to 2.85 million people. Furthermore, if the candidate NHES is built, replacement of coal power plants with nuclear could provide high quality jobs with a corresponding need for higher education for those on the reservation. 


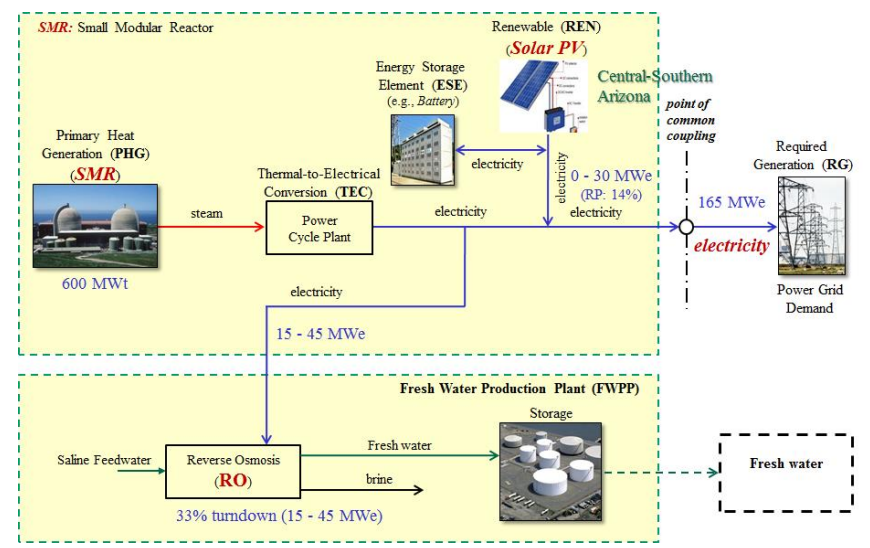

Figure 8: Network topology for NHES_Arizona with a flexible electrical load.

\subsubsection{Equipment layout}

Figure 8 shows a high-level process diagram of NHES_Arizona, which include the following main components:

- A SMR similar to that used in NHES_Texas; and BOP as follows:

- steam turbines similar to those used NHES_Texas,

- renewable power generation produced by PV solar stations, with capability of up to 30 MWe. This renewable power generation capacity was selected to accordingly correspond to the selected nominal capacity for the fresh water production plant (FWPP). Greater levels of renewable integration is possible by accordingly modifying this initial NHES configuration,

- electrical storage similar to that used in NHES_Texas,

- FWPP able to utilize electricity up to $45 \mathrm{MWe}$, and convert saline or brackish water into fresh water and brine. This particular component scale was selected considering the anticipated water needs in the Arizona region. FWPP can be expanded as the need for fresh water increases and renewable energy is phased in,

- enough saline or brackish feedwater to support the fresh water production plant,

- electric grid connected to the NHES at a point of common coupling and consuming electricity up to 165 MWe.

As indicated in Figure 8, the current configuration differs from NHES_Texas in that there is only one steam generation cycle in NHES_Arizona. The process steam coming out of the steam generator is exclusively directed to the power cycle for electricity production, with a typically small amount bypassed through a PCV in case of pressure deviation, both of which are merged together before being condensed into water, and delivered as feedwater to the steam generator. These form the only steam cycle in NHES_Arizona, preserving the steam flow mass in the system. 


\subsubsection{Components}

PHG is the primary source of energy in NHES_Arizona. PHG includes a SMR generating heat, and a steam generator, which transfers heat to the feedwater coming from the BOP. The superheated steam of the steam generator is then delivered to the power cycle to drive a series of three steam turbines paired with an electrical generator in order to produce the required additional electricity to meet the demands from both the electric grid and the water desalination plant, considering contribution from the renewable generation.

NHES_Arizona is operated in a manner such that the electricity produced by the power cycle and the PV solar stations are managed by a supervisory controller and distributed to the electric grid and the water desalination plant according to their individual needs and an optimal strategy determined by an operations optimizer (supporting online economic operations optimization, see [19]).

The FWPP considered in NHES_Arizona consists of the following unit operations:

- set of pumps to push water towards reverse osmosis (RO) membranes,

- RO membranes to diffuse water from brine,

- The connection of NHES_Arizona to the electric grid is similar to that devised for NHES_Texas; hence, no additional description is provided here.

The readers are referred to [9] for the details of the FWPP.

\subsubsection{Controls}

NHES_Arizona exploits the same hierarchal control strategy as that described for NHES_Texas. This strategy dynamically determines the amount of electricity that needs to be diverted to the water desalination plant and updates the local controller accordingly (e.g., change the set point, update the control gain) to ensure the electricity distributions into the electric grid versus the FWPP meet the supply requirements. Numerous feedback controllers are augmented as low level controllers to maintain desired conditions. The pressure in the steam cycle is controlled by a PCV, regulating the steam flow that is bypassing the TEC system. The flow into the steam turbines is controlled by three FCV, one for each steam turbine. These three FCV work accordingly to guarantee the power cycle generates the precise amount of electricity needed, which is full load production in this case. The steam going through the steam turbines and the steam bypassing the TEC system are merged together, before it is condensed into water, which is heated to 215.6 ${ }^{\circ} \mathrm{C}$ before feeding it into the steam generator. This is accomplished by a heat exchanger under temperature control regulation. The feedwater flow into the steam generator is regulated by a second temperature control valve, which maintains the temperature of the outflow steam of the steam generator at desired value of $312.8^{\circ} \mathrm{C}$.

\subsubsection{Operations}

There are two units for electricity generation in NHES_Arizona; namely, the TEC system and REN. These two electricity generation units are operated accordingly to deliver the electricity generation requested by the electric grid operator (e.g., an ISO, RTO) or by an operations optimizer. In either case, the power delivered to the electric grid is assumed to be less than or equal to 165 MWe. This electricity production is the first output of NHES_Arizona. The second output is fresh water, which is produced by the 
desalination plant from electricity distributed by the supervisory controller. Unlike the case of NHES_Texas where an AHG is used to compensate for the variability of the steam flow delivered by the SMR to the chemical plant, here the electricity consumed by the water desalination plant is supplied by the nuclear power plant transmission system. The water desalination plant has a capacity of $45 \mathrm{MWe}$, but is operated to maintain a minimum electricity consumption of 15 MWe. The SMR is sized for full load operation, i.e., $600 \mathrm{MWt}$, such that it is capable of generating (without renewable contribution) sufficient process steam to meet the maximum electric grid demand (i.e., $165 \mathrm{MWe}$ ) plus the minimum consumption for desalination operations (i.e., $15 \mathrm{MWe}$ ). Under the extreme situation that the electric grid requests from this NHES a constant electricity generation of 165 MWe in the absence of renewable contribution, the electrical power provided to the water desalination plant is just $15 \mathrm{MWe}$; in the event of nonzero renewable contribution, the desalination plant may be then operated beyond the minimum of 15 MWe under the guidance of a supervisory controller. In the worst renewable generation case scenario, the water desalination plant would produce approximately $40 \%$ of its maximum fresh water production. This is contrary to the NHES_Texas case, in which the GPP is maintained at a full production mode regardless of the absence of the renewable contribution. By enabling the water desalination plant to use excess electricity, NHES_Arizona provides opportunities for flexible energy management, providing various ancillary services, such as operating reserves (e.g., regulating, ramping, load following, and supplemental reserves), and attractive operational flexibility for value (technical and/or economic) optimization. Changes in net load do not affect $\mathrm{CO}_{2}$ production in NHES_Arizona as no $\mathrm{CO}_{2}$ emission occurs here.

NHES_Arizona can increase or decrease its electricity production when requested in order to provide ancillary services. For example, if the electricity production is $160 \mathrm{MWe}$ at a given time with 10 MWe coming from the PV solar units, then NHES_Arizona can potentially increase or decrease electricity production to as high as 175 MWe or as low as $145 \mathrm{MWe}$, respectively. Accordingly, the water desalination plant would be operated at its minimum or full production mode consuming 15 MWe to 45 MWe. In other words, assuming a 10 MWe constant PV solar contribution, NHES_Arizona can accept a change of up to 30 MWe in its electricity production, a capacity that is large enough to bid into ancillary service market. Furthermore, since the water desalination plant can be operated at its minimum turndown for as long as requested, NHES_Arizona can maintain the change in its electrical production for large time periods.

\subsubsection{Dynamic models}

Figure 9 shows the top level model for NHES_Arizona. As seen from this screen capture, twelve main subsystems can be identified as follows:

1. Physical devices: Nuclear SMR, feedwater heater and thermal distribution center, power generation, reverse osmosis water desalination plant, PV solar generation, battery based power smoothing, electric grid

2. Control devices: Governor, power cycle supervisor, many low level controllers (embedded within corresponding subsystems; not shown), control bus

3. Evaluation Module: System evaluation (used to facilitate evaluation of multiple scenarios 


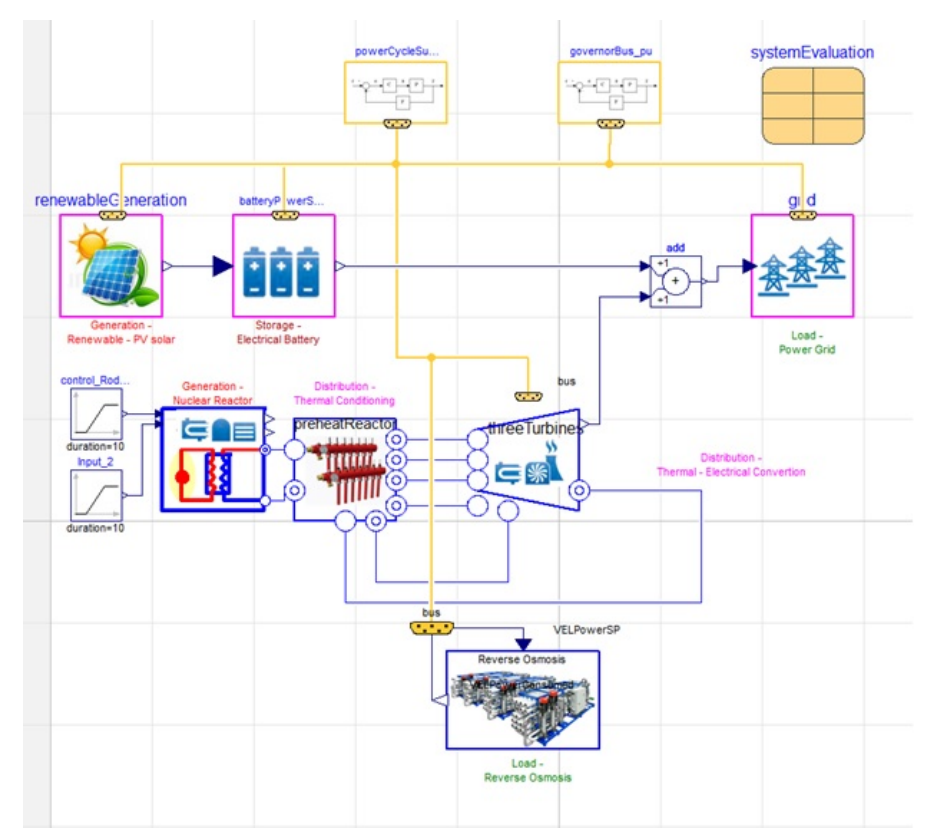

Figure 9: Top level model for NHES_Arizona in Modelica.

\section{TECHNICAL PERFORMANCE ANALYSIS METHODOLOGY}

Numerous tests were carried out to characterize the dynamic technical properties of the two regional NHES configurations, to compute several technical FOM, and to demonstrate their capability to manage high levels of renewable penetration, while supporting multiple commodity production and ancillary services. Such enhanced understanding of the dynamic characteristics of these advanced energy systems can assist policy makers, as well as designers and engineers, to best devise practical solutions for accommodating the high variability of renewable generation and for effectively working towards increased use of clean energy.

\subsection{Figures of merit}

The technical FOM considered in this dynamic study are those typically relevant for electric grid applications. These include:

- Electric power frequency stability

- Maximum renewable penetration that can be accommodated

- Maximum renewable variability that can be accommodated

- Minimum storage requirement

- Response time and ramp rate

- Load following response

- Operating reserve capacity

- Minimum turndown of integrated systems 
- Startup/shutdown time

In particular, the system technical performance is evaluated in terms of the FOM listed above, observing in all cases the variation of the electric power frequency. Consequently, time series of the electric power frequency (or equivalently, turbine shaft speed) are analyzed and at times plotted when deemed productive to show the high quality of electrical frequency regulation provided by the NHES configurations. Furthermore, the production rate of alternative commodities and/or their quality (e.g., salinity of the fresh water product) are also used as performance indicators. Dynamic characteristics of the NHES configurations are also measured in terms of response time and other metrics relevant to ancillary services. For instance, the response time by which the considered NHES configuration is capable of redistributing energy following a renewable/demand change is tested and compared to the operational requirements for participation in wholesale market services.

Likewise, the ancillary service markets explored in this paper also include load following, spinning and non-spinning reserves, and supplemental reserves [23-25]. Regulation provides real time adjustments to maintain the desired frequency and requires response time and ramp rate on the minute timescale and must be maintained for 15 minutes at a time [25]. Load following matches the real time demand, requires roughly 10 minutes response time and must be maintained for 10 minutes to several hours [25]. Spinning reserve and non-spinning reserve are additional capacity available in the event of a generator failure or other contingency. Spinning reserve requires immediate response and a total response time less than 10 minutes and must be maintained for up to 2 hours [25]. Non-spinning reserve does not require immediate response but has the same requirements in total response time and duration as spinning reserve [25]. Supplemental reserve must respond in less than 30 minutes and be maintained for 3 hours. As shown in this study, the selected NHES configurations can respond sufficiently fast and for sufficiently long duration, to participate in the ancillary service market.

\subsection{Test Plan}

\subsubsection{Impact of renewable penetration}

The renewable penetration (RP) is defined as the ratio of the maximum power generation delivered by REN (renewable) versus the maximum total power generation produced by both REN and PHG, all converted to the form of electrical power. In order to assess the impact of RP, the value of RP is varied to determine its effect on key process variables (e.g., electrical frequency) and to assess whether the particular NHES can satisfactorily accommodate the maximum level of renewable penetration that it is designed for.

\subsubsection{Impact of renewable variability}

The next test aims to characterize how the NHES responds to variability of the renewable energy source. Even though actual renewable energy generation profiles are used in this study, an adjustable input signal is also employed to emulate it, which thus allows a user to manipulate the variability of renewable, observe its effect on process variables (e.g., electrical frequency), and assess whether the particular NHES can satisfactorily accommodate fast-varying renewable power changes. Specifically, the generic trapezoid signal illustrated in Figure 10 is utilized to describe renewable generation where the width and amplitude are as denoted, and the ramp rate is defined as the ratio of $\Delta P$ over $\Delta T$ 
of the uphill/downhill. A particular value for ramp rate may be selected, for example, from finding out worst case scenario of renewable generation variation change in a given geographical area.

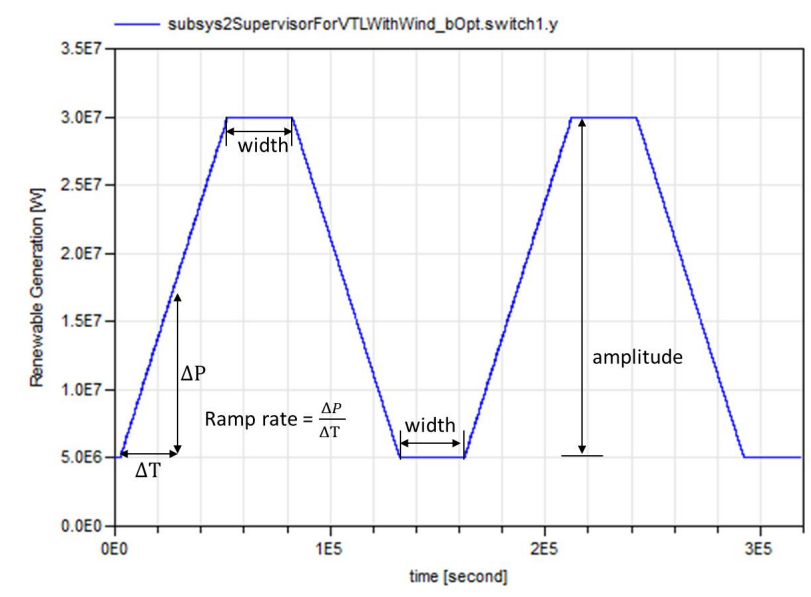

Figure 10: Trapezoidal input signal used for renewable generation.

\subsubsection{Power smoothing for renewable variability attenuation}

When used for power smoothing, the battery acts as a low pass filter with its frequency significantly affecting the degree of variability removal. This test is employed to characterize the NHES dynamic properties in response to different battery selection. The power smoothing effect of batteries is modeled as first order differential equations and hence, the time constant, $\tau_{E S E}$, is used, which is the inverse of its frequency.

\subsubsection{Ancillary service: response time and ramp rate}

Depending on how quickly the NHES configuration can begin responding, change its response, and deliver the requested change, it can be utilized for various ancillary services such as regulating, ramping and contingency reserve. This test is to demonstrate how fast the NHES configurations can respond to an electrical demand change. In this test, the demand curve has the profile shown in Figure 11, where the parameters startTime, startValue, duration and height are as denoted. Note that, by using this profile, the duration can be made to approach zero (e.g., for simulating a step change), while having the flexibility to generate a less aggressive ramping signal as needed to meet specified grid service requirements.

\subsubsection{Ancillary service: load following}

In order to demonstrate the capability of the NHES configurations to provide load following reserves, simulations are conducted using actual hourly demand profiles for West Texas and Phoenix Arizona, respectively, to show how the system performance may be affected when the variability to the NHES is introduced from the demand side. 


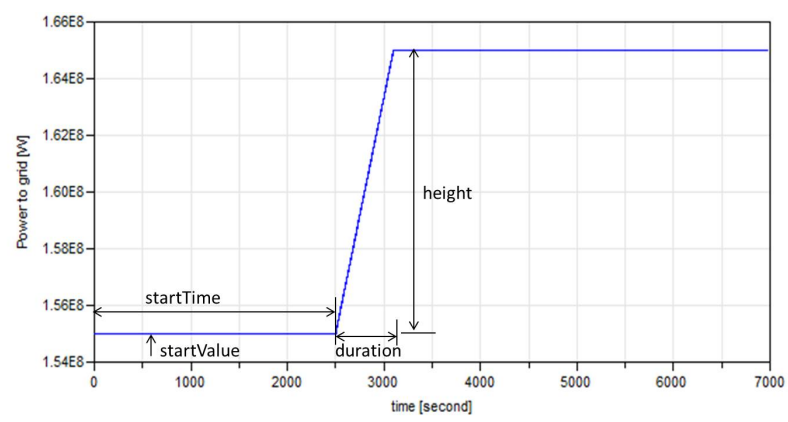

Figure 11: Ramp signal as electrical generation to the electric grid.

However, the demand profiles are accordingly modified in a manner to assure that the maximum electrical generation/load capacities of components within selected NHES are not exceeded.

\subsubsection{Ancillary service: operating reserve}

This test is to evaluate the operating reserve capacity that the selected NHES configurations can provide to the electric grid. In particular, a sharp increase in the electric grid demand is introduced in the simulation. For this test, the demand curve has also the profile shown in Figure 11. Simulation with this type of curve is performed to show the ability of the NHES configurations to meet the sharp demand increase, while providing high quality electricity. This test is also used to evaluate the minimum turndown and startup and shutdown time characteristics of selected NHES solutions.

\subsection{Renewable and Demand Assumptions and Simulation Setup}

\subsubsection{Wind energy}

For long term prediction of wind power, physical models may be utilized; however, they often do not provide sufficient accuracy in short term prediction for efficient power management. Likewise, while statistical methods may provide accurate short term results, their reliability in long term prediction is questionable [26]. In this work, renewable energy generation is modeled as time series input signals based on wind speed data obtained from the Eastern Wind dataset maintained by NREL (National Renewable Energy Laboratory). The data series used in this work is for a site in West Texas. Figure 12 shows a representative seven days of the dataset (sampled at every 10 min, with linear interpolation used to fill data gaps) to illustrate the variability of power production, which must be accommodated to make wind power more generally useful. Scaled versions of this time series are used to model different levels of renewable penetrations.

The wind speed data is then converted to wind power input to the battery, assuming a given number of wind turbines, each rated at 3.6 MWe and located on a 2 square kilometer site for a maximum of about 36 MWe generation at full production (hence assuming about ten wind turbines), according to the function shown in Figure 13. There are four operating regimes for a wind turbine, separated by critical wind speed values. At wind speeds below a minimum cut in velocity, there is insufficient kinetic energy in the 


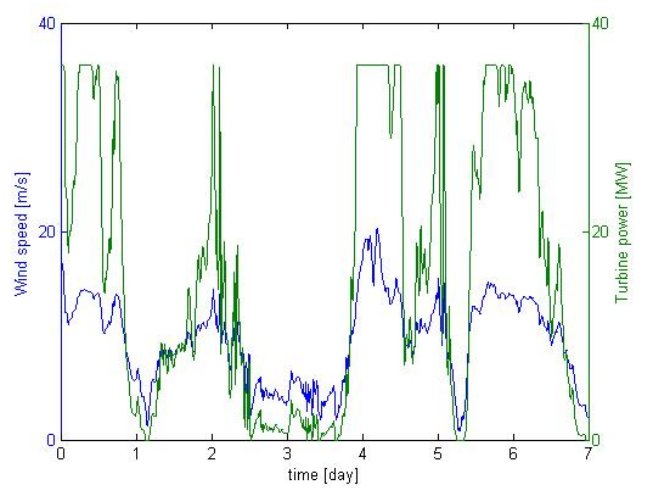

Figure 12: Wind speed and turbine power for a period of seven days in NHES_Texas.

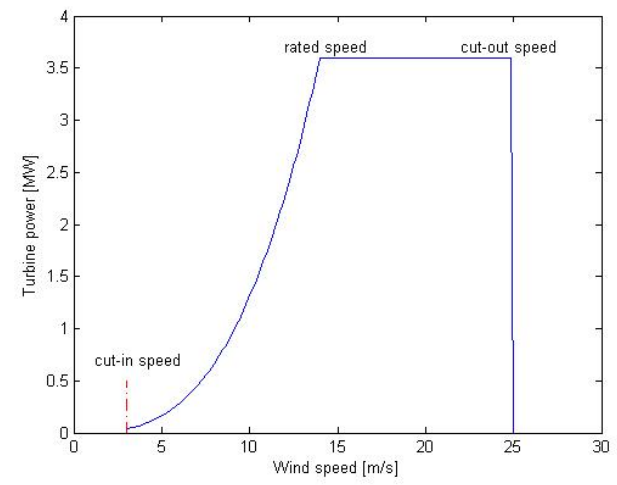

Figure 13: Turbine power vs. wind speed.

wind to cause any rotation, thus no electrical power is produced. At wind speeds above a cut out velocity, a braking system is activated for safety reasons, and again no power is produced. Between the rated and the cut out velocity values, the turbine provides a steady maximum power level, also known as the rated power. For the range between the cut in and rated speeds, the power is calculated using Eq. (1):

$$
E_{R E N}:=0.5 \eta \rho U^{3} \frac{\pi d^{2}}{4}
$$

where $\eta$ is the conversion efficiency of the wind turbine, $\rho$ is the density of the air at the site, $U$ is the wind velocity, and $d$ is the diameter of the turbine blades. In essence, Eq. (1) relates the power delivered by the turbine to the amount of kinetic energy available in the wind, via an overall lumped efficiency number. At a typical site, the majority of the turbine operation occurs in this regime. The values for each parameter in Eq. (1) are: $\eta=35 \%, \rho=1.17682 \mathrm{~g} / \mathrm{m}^{3}, d=90 \mathrm{~m}$. 


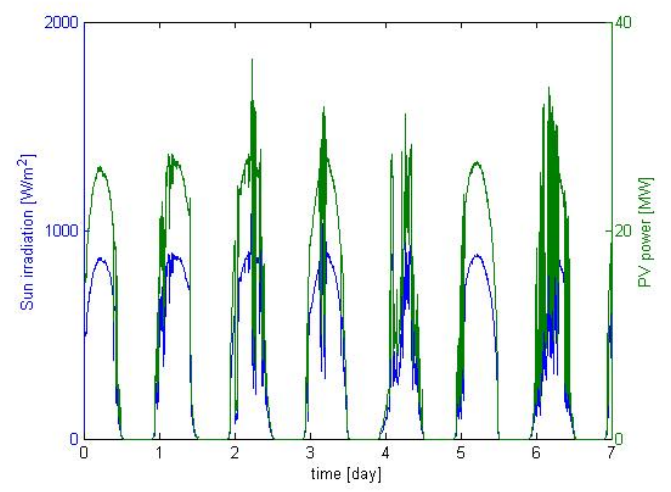

Figure 14: Solar irradiation and PV solar power for a period of seven days in NHES_Arizona.

\subsection{2. $P V$ solar energy}

The PV solar energy generation is modeled as time series input signals based on solar irradiation data (i.e., Direct Normal Irradiance, Diffuse Horizontal Irradiance) as well as air temperature data obtained from the Southwest Solar Research Park dataset (Phoenix, Arizona) maintained by NREL. Given time series data for Direct Normal Irradiance (DNI) and Diffuse Horizontal Irradiance (DHI), the total amount of irradiation received by a PV module, denoted as $G_{T}$, is given by Eq. (2) [27, 28]:

$$
G_{T}:=D N I \times \cos (\beta+\delta-l a t)+D H I \times \frac{180-\beta}{180}
$$

where $\beta$ is the tilt angle of the PV module from horizontal whose typical optimal value is slightly less than the site latitude [29], $\delta=23.45^{\circ} \sin (360(284+D O Y) / 365)$ is the declination angle [30], lat is the latitude of the site and DOY is the day of the year. Figure 14 is a plot of seven representative days of the irradiation on a PV module and the electrical power generated using the conversion described below. Note that while more complex conversion formulas can be found in literature (e.g., [31]), the above formulation is chosen to balance computational complexity and simulation speed.

A PV module receives solar irradiation, and converts it to electrical power. The generated power depends on the amount of irradiation received by the PV module and the ambient temperature at which the PV module is operating. In order to characterize the relationship among the PV power output, solar irradiation, and the ambient temperature, several mapping functions were studied in [28, 32, 33]. In this study, the power output from the PV module is modeled according to:

$$
P=G_{T} \tau_{p v} \eta_{r e f} A[1-\gamma(T-25)]
$$

where $G_{T}$ is the solar irradiation arriving on the PV module, $\mathrm{T}$ is the ambient temperature, and $\mathrm{A}$ is the total area of the $\mathrm{PV}$ module receiving solar irradiation. The values of parameters in Eqs. (2) and (3) used in simulation are: $\tau_{p v}=90 \%, \eta_{\text {ref }}=15 \%$, $\beta=33.42^{\circ}, \gamma=0.45 \%$ 


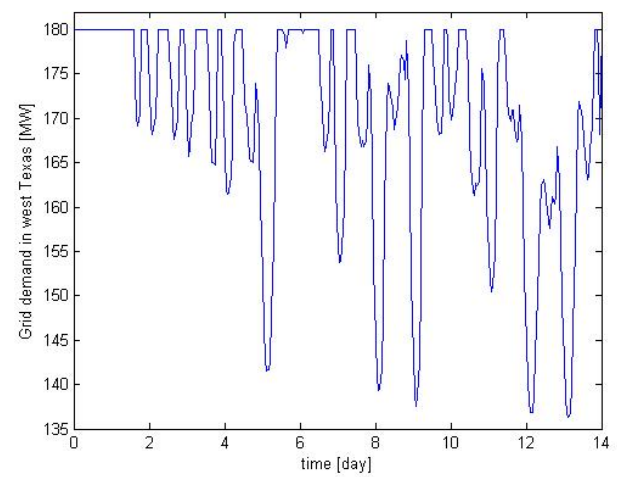

Figure 15: Hourly electricity demand considered for NHES_Texas.

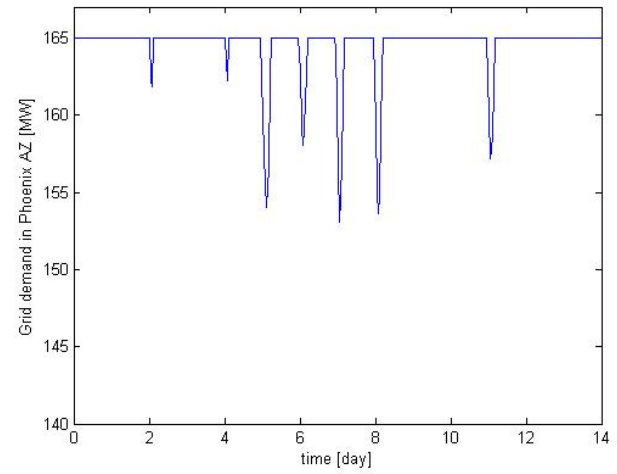

Figure 16: Hourly electricity demand considered for NHES_Arizona.

\subsubsection{Electric grid demand}

Two distinct time series of actual hourly load data collected from Texas and Arizona are used to model the required electric grid generation for the load following tests. The hourly load data for Texas was published by Electric Reliability Council of Texas and is associated with the west region of Texas. The other hourly load data for Arizona was published by Federal Energy Regulatory Commission and corresponds to Phoenix, AZ. Both time series data are scaled so that the peak load is saturated at 180 MWe and $165 \mathrm{MWe}$, respectively, with the variability being preserved for data below their corresponding peak. Figures 15 and 16 show the scaled version of hourly load data from Texas and Arizona, respectively. 


\section{PERFORMANCE RESULTS}

This section presents technical estimates obtained from conducting the various tests described in Section 3. Time series are plotted with time units given in seconds unless otherwise indicated. In order to assess whether a given NHES configuration is capable of satisfactorily responding to the particular test under consideration, a key process variable that should always be observed is the electrical power frequency (or turbine shaft speed) or, equivalently, the corresponding electrical and mechanical torque at the steam turbine shaft. This is because the electrical power frequency (or turbine shaft speed) must be managed in a very tight band of $0.5 \mathrm{~Hz}$ (or $3.14 \mathrm{rad} / \mathrm{s}$ ) around the systems design frequency of $60 \mathrm{~Hz}$ (or $377 \mathrm{rad} / \mathrm{s}$ ) to ensure electric grid reliability; otherwise, the particular NHES would be disconnected from the electric grid. There are additional process variables that should be tracked (e.g., steam generator inlet and outlet temperature, pressure, and mass flow rates) to assess whether safety requirements are met as well. On a case by case basis, other process variables (e.g., the nuclear generated steam diverted for gasoline production in NHES_Texas and the concentration of fresh water produced in NHES_Arizona) are important in determining whether the variability introduced by energy sources and/or loads is satisfactorily managed within the given NHES. As plotting all relevant process variables needed to comprehensively assess the behavior of the given NHES under each test is too lengthy, the next sections provide selected time series plots of process variables deemed as most interesting. Regardless of this reporting strategy, all key process variables were accordingly collected and used as necessary to assess whether the dynamic behavior of the given NHES is satisfactory under each test.

\subsection{NHES_Texas}

This section presents results obtained as they apply to the HES with flexible thermal load (NHES_Texas).

\subsubsection{Impact of renewable penetration}

In this test, the system performance is evaluated for increasing renewable penetration, assuming a constant electrical generation to the electric grid of $180 \mathrm{MW}$. Figure 17 shows the time series of the steam turbine shaft speed when considering eight and twelve wind turbines. Notice that the variation of shaft speed (due to time-varying changes in renewable generation) is well within the acceptable band.

Likewise, Figure 18 shows the flow rate of the steam produced by the steam generator associated with the SMR (bottom, blue line labeled PHG steam flow) as well as that produced by the NG fired auxiliary boiler (middle, red line labeled AHG steam flow), the latter being used to assure that by adding it to the PHG steam flow a constant high pressure steam flow (top, green line labeled header steam flow) can be supplied to GPP for gasoline production when considering eight and twelve wind turbines. Notice that this constant header steam flow requirement leads to the PHG and AHG steam flow profiles being opposite to each other. The corresponding magnitudes of variation of these two flows increase as the magnitude of renewable generation increases. Due to the complementary action of these two PHG and AHG generated steam flows, the GPP can successfully be operated in a constant full load mode, even though the SMR delivers a time varying thermal energy for gasoline production that varies as a function of the variability introduced by the renewable (wind) source. These results suggest that high 


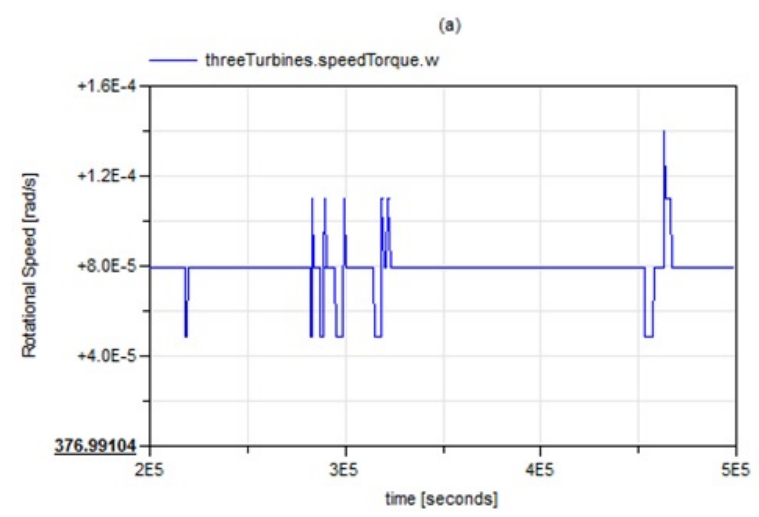

(b)

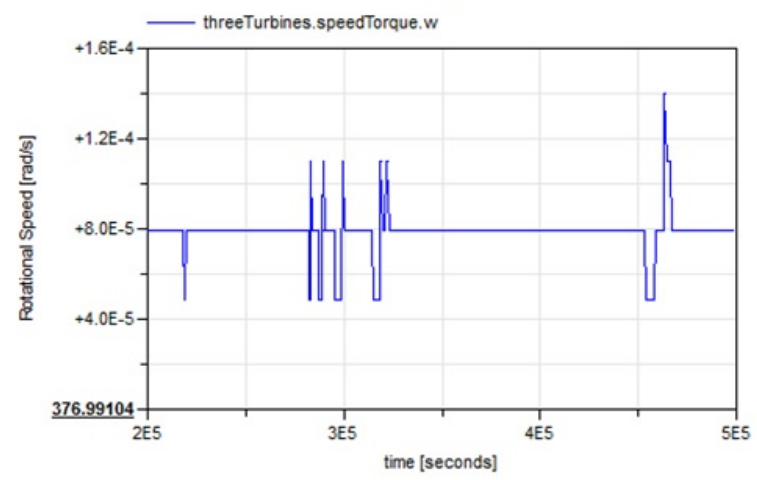

Figure 17: Steam turbine shaft speed for: (a) 8 wind turbines; (b): 12 wind turbines (NHES_Texas).

penetration levels of renewable energy can be effectively managed by NHES_Texas, while maintaining adequate dynamic performance.

\subsubsection{Impact of renewable variability}

In this test, the renewable generation is characterized by a trapezoidal signal as shown in Figure 10, with a width of $500 \mathrm{~s}$, two ramp rates of 0.03 and $0.3 \mathrm{MW} / \mathrm{s}$ and amplitude of 25 MWe such that the renewable penetration is $12 \%$. These ramp rates were selected after identifying that the maximum ramp rate observed on the actual wind power data collected was $0.05 \mathrm{MWe} / \mathrm{s}$ without power smoothing. It is also assumed a constant electrical generation to the electric grid of 180 MWe. Figure 19 shows the time series of the steam flow generated by the steam generator that is diverted for gasoline production in response to a time varying renewable generation. As the renewable generation increases, the steam flow diverted to gasoline production accordingly increases as less steam flow is needed for electrical production at the turbines; a similar logic applies regarding the opposite way. The frequency of this variation increases as the ramp rate of renewable generation increases.

Likewise, Figure 20 shows the time series of the turbine shaft speed. As the turbine 
(a)

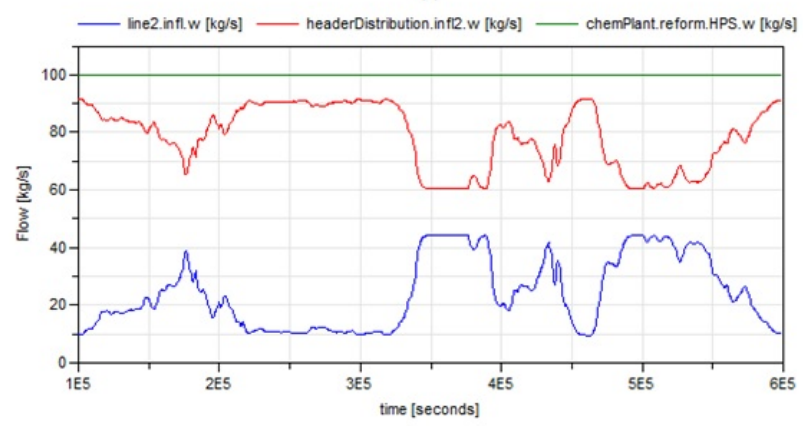

(b)

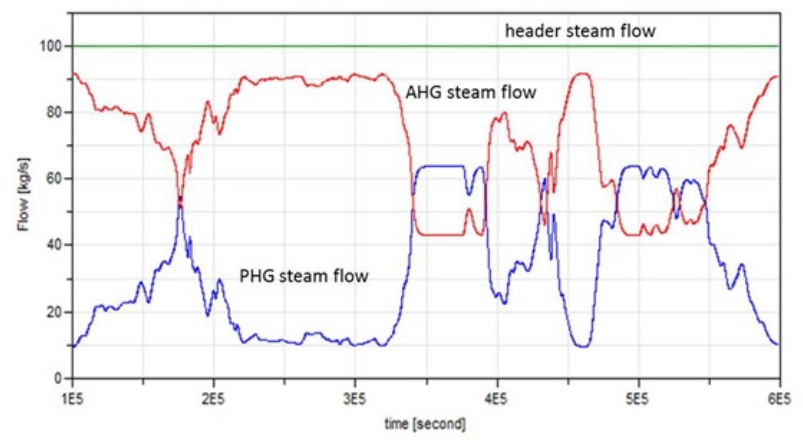

Figure 18: Nuclear (PHG), NG fired boiler (AHG), and header steam flows (bottom-blue, middle-red, and top-green lines, respectively) for: (a) 8 wind turbines; (b) 12 wind turbines (NHES_Texas). 

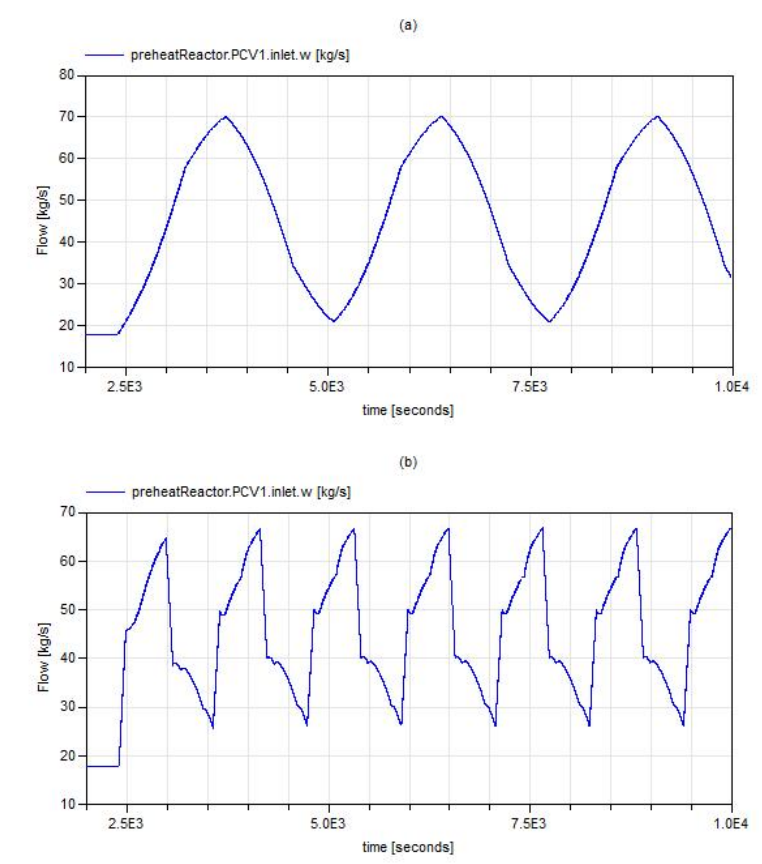

Figure 19: Steam flow diverted for gasoline production under a renewable ramp rate of: (a) $0.03 \mathrm{MWe} / \mathrm{s}$; (b) $0.3 \mathrm{MWe} / \mathrm{s}$ (NHES_Texas). 

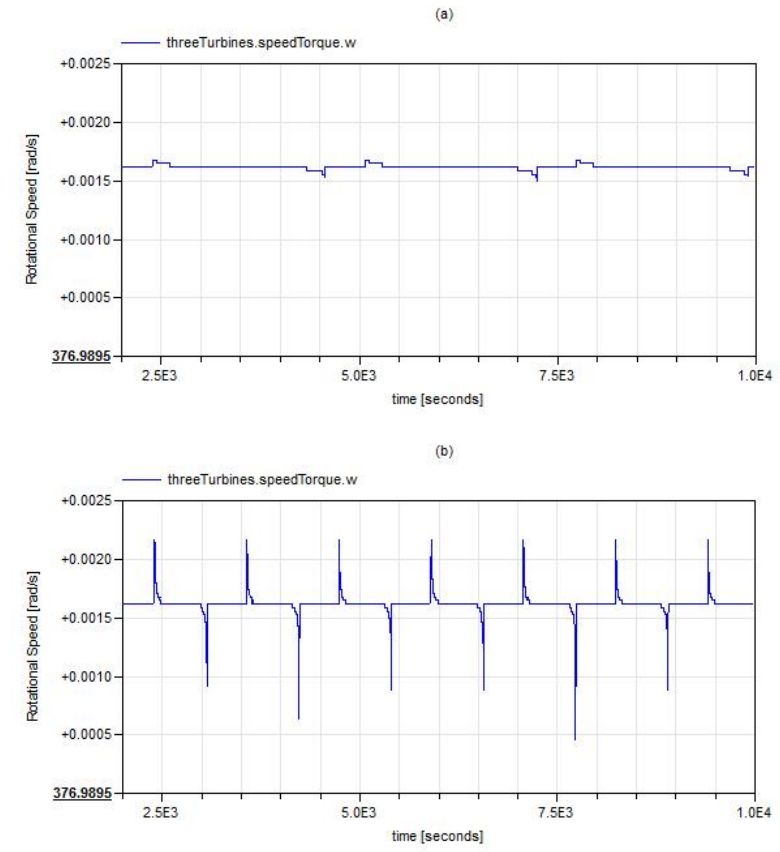

Figure 20: Steam turbine shaft speed under a renewable ramp rate of: (a) $0.03 \mathrm{MWe} / \mathrm{s}$; (b): $0.3 \mathrm{MWe} / \mathrm{s}$ (NHES_Texas).

shaft speed is kept well within the required range by rapidly diverting steam for gasoline production, these results suggest that high variability of renewable energy can be effectively managed by NHES_Texas, while maintaining adequate dynamic performance.

\subsubsection{Power smoothing for renewable variability attenuation}

In this test, the system performance is evaluated for two values of power smoothing provided by an electric battery, assuming a constant electrical generation to the electric grid of 180 MWe and an actual Texas wind profile with ten turbines. Figures 21 and 22 show the renewable generation profiles before and after the power smoothing effect introduced by the electric battery for different values of power smoothing time constants. For each figure, the instantaneous power output differences and the areas of continuous charge/discharge cycles correspond to the particular charge/discharge power and energy storage values, respectively, accommodated by the battery. While the largest difference in the instantaneous power output corresponds to the minimum charge/discharge power required for the battery, the largest single contiguous area corresponds to its minimum required energy storage capacity. In this case, the battery needs to have a power rating of $17 \mathrm{MWe}$ and storage capacity of $16 \mathrm{MWe}-\mathrm{hr}$ to achieve the smoothing effect reported in Figure 21, and a power rating of 22 MWe and storage capacity of 90 MWe-hr to achieve the smoothing effect reported in Figure 22. Thus, the bigger the battery is, the more power smoothing can be achieved on the electrical power obtained from renewable generation. Since the capital and operational costs of the battery are directly related 


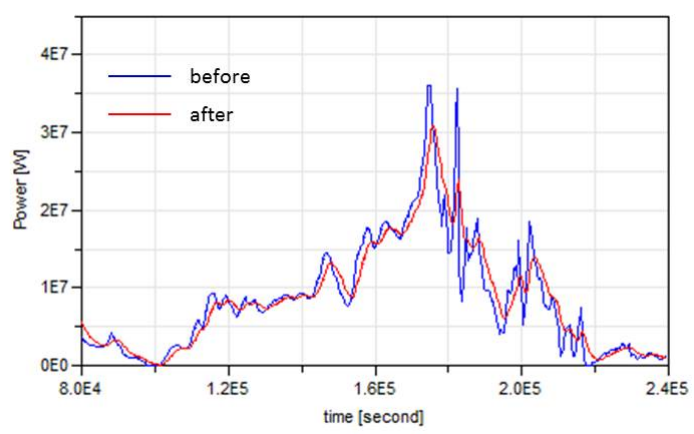

Figure 21: Renewable generation before and after power smoothing with a time constant of 1800s (NHES_Texas).

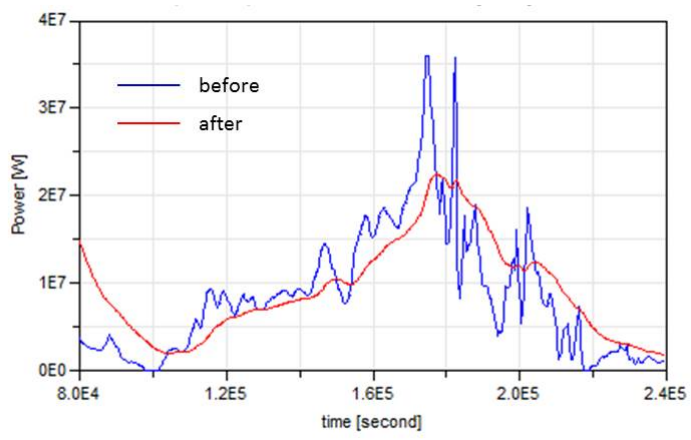

Figure 22: Renewable generation before and after power smoothing with a time constant of 9000s (NHES_Texas).

to its size, this test provides a benchmark when considering the trade off between the benefit of incorporating power smoothing to smooth the variability introduced by the renewable source versus the cost of installing system scale ESE.

\subsubsection{Ancillary service: Response time and ramp rate}

In order to assess the response time and ramp rate characteristics of NHES_Texas, a demand profile with a step change as in Figure 11 is used, with a height of $25 \mathrm{MWe}$, duration of $0.01 \mathrm{~s}$, startValue of $155 \mathrm{MWe}$, and startTime of $2500 \mathrm{~s}$. A constant wind profile of $18 \mathrm{MWe}$ was also assumed. In particular, the transient is initiated at $2500 \mathrm{~s}$ via a $25 \mathrm{MWe}$ increase in electrical grid demand (from an initial generation level of $155 \mathrm{MWe}$ ). This increase is completed within $0.01 \mathrm{~s}$ (hence a very high ramp rate). Figure 23 shows the time series for both the electrical and mechanical torques at the steam turbine shaft. It is important to remark that the steam turbines are controlled by the governor, which tries to keep constant the shaft rotational speed. To this end, the governor regulates the flow rates of steam to the steam turbines (by manipulating their steam control valves) in order to exert the necessary mechanical torque on the turbine shaft to equally 


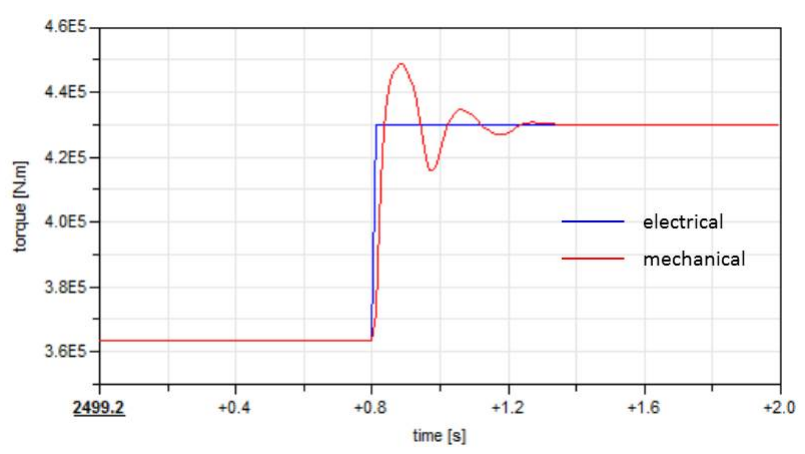

Figure 23: Electrical and mechanical torque at the steam turbine shaft (NHES_Texas).

oppose the electrical torque exerted on the turbine shaft by the net load (i.e., demand minus renewable generation). As can be seen, it requires 0.6 seconds for the mechanical torque to match the corresponding electrical torque change and settle to its final value. This fast response is likely due to effective control strategies implemented, but may also be attributed to the potential absence of engineered constraints (imposed for safety, for example) in the model that may more realistically characterize all key components of concern. Additional constraints will be implemented in future model refinement. Regardless, this result strongly suggests that NHES_Texas can begin responding very quickly and change its response fast enough to participate in the electric grid ancillary services considered.

\subsubsection{Ancillary service: Load following}

As suggested by the previous test, NHES_Texas is predicted to respond fast enough to participate in the ancillary services considered. This test is to further demonstrate the capability of NHES_Texas for load following. A Texas region actual profile is assumed for the electrical generation to the electric grid and a constant wind profile of $18 \mathrm{MWe}$ Figure 24 shows the time series of the flows going to the steam generator (top, blue line labelled Steam generator) and that diverted to the secondary boiler for delivery towards gasoline production (middle, red line labeled Secondary boiler), in addition to the steam flow generated by the auxiliary steam boiler (bottom, green line labeled NGfired boiler) for supporting constant gasoline production at the GPP. These last two curve profiles are similar in trend to those plotted and discussed for Fig. ??. The results suggest that NHES_Texas can act as a highly responsive device to meet load following needs by accordingly delivering the necessary electricity generation profile demanded by the electric grid, while correspondingly adjusting itself to maintain adequate operating conditions.

\subsubsection{Ancillary service: Operating reserve}

This test is to further demonstrate the operating reserve capacity that NHES_Texas can provide to the electric grid. A demand profile with a step change as in Figure 11 is used, with a height of $10 \mathrm{MWe}$, duration of $600 \mathrm{~s}$, startValue of $155 \mathrm{MWe}$, and startTime of $2500 \mathrm{~s}$. A constant wind profile of 18 MWe was also assumed. In particular, the 


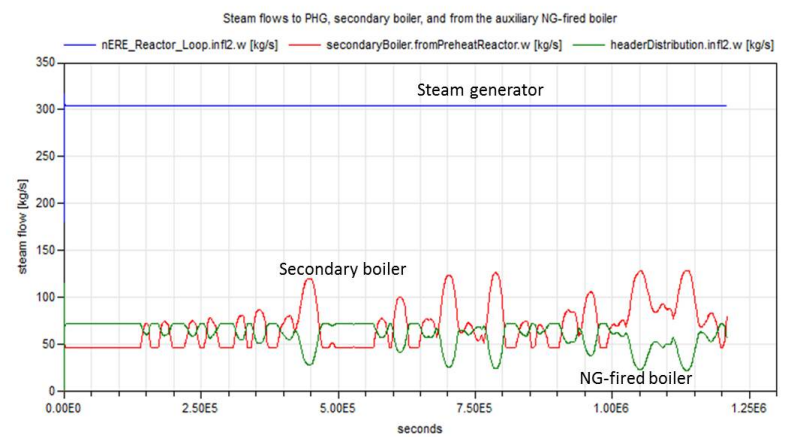

Figure 24: Steam flows to steam generator, secondary boiler, and from the NG fired boiler (top-blue, middle-red, and bottom-green lines, respectively) (NHES_Texas).

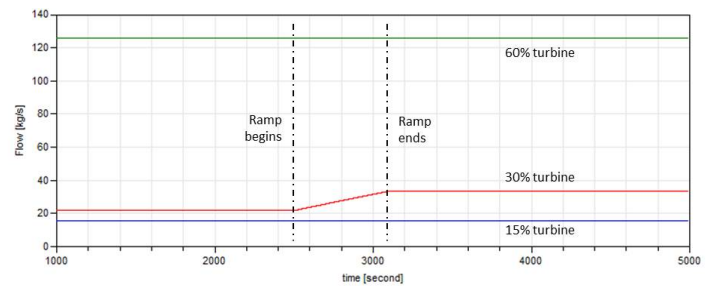

Figure 25: Steam flows to the three 15\%, 30\%, 60\% turbines (NHES_Texas).

requested electricity increases from 155 MWe at $2500 \mathrm{~s}$ to 165 MWe over 10 minutes, which corresponds to the ancillary service requirement for the considered operating reserve. Figure 25 shows the time series for the steam flows going to each of the three installed turbines, respectively. As shown in this figure, the governor quickly adjusts the steam flows entering each turbine in order to effectively accommodate the increased demand. In particular, the governor commands the opening of the steam flow valve associated with the $30 \%$ turbine in order to increase its steam flow, hence its electricity generation, in order to meet the increased demand. Likewise, Figure 26 shows the time series for the temperature of the steam flow leaving the steam generator. The temperature response from time zero to $2500 \mathrm{~s}$ corresponds to the system initialization from cold shutdown to full operation. Notice the very small perturbation from $2500 \mathrm{~s}$ and beyond in the temperature response caused by the indicated demand increase.

These results suggest that NHES_Texas can provide a large spinning capacity. Being essentially in standby mode with respect to the electric grid, this configuration does essentially exhibit zero startup and shutdown times to deliver the requested operating reserve services. This is achieved by the fact that NHES_Texas offers more than one energy utilization avenue, allowing steam to be diverted to increase or decrease electricity generation quickly when demanded. 


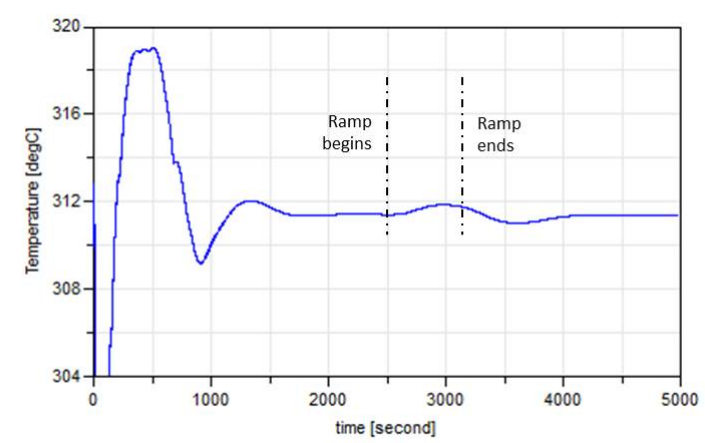

Figure 26: Temperature at steam generator outlet flow (NHES_Texas).

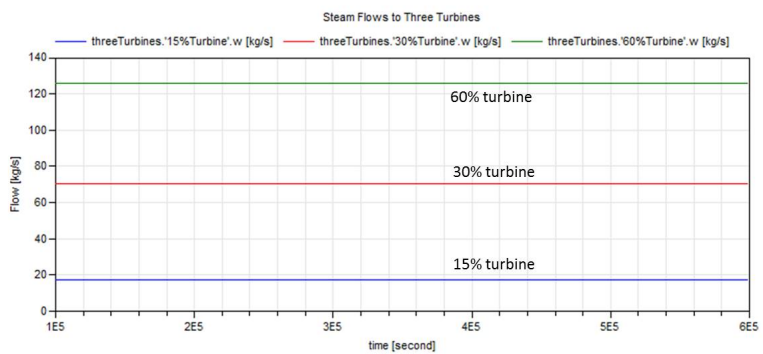

Figure 27: Steam flows entering the three turbines for 5 and 8 PV solar units (NHES_Arizona).

\subsection{NHES_Arizona}

This section presents results obtained as they apply to the HES with flexible electrical load (NHES_Arizona).

\subsubsection{Impact of renewable penetration}

In this test, the system performance is evaluated for increased renewable penetration, assuming a constant electrical generation to the electric grid of 165 MWe. Figure 27 shows the time series for the steam flows going to each of the three installed turbines, respectively, when considering eight PV units. As shown in this figure, the steam flows entering each turbine are essentially unperturbed by the variability of renewable generation due to the flexible electrical load characteristic offered by the reverse osmosis (RO) desalination plant. In other words, the power cycle is largely unaffected by changes in renewable energy generation because excess electrical generation is quickly absorbed by the desalination plant.

Although not shown to free page space, it was observed that the electrical power frequency is maintained and does not change even with the inclusion of time varying renewable generation as determined from actual Arizona data. These results suggest that high penetration levels of renewable energy can be effectively managed by NHES_Arizona, while maintaining adequate dynamic performance. 
(a)

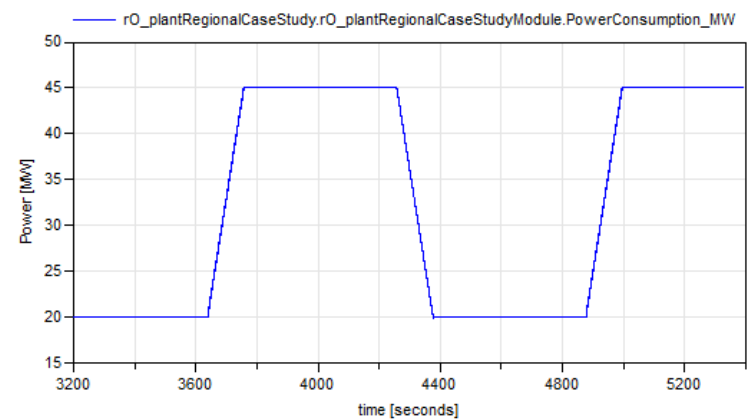

(b)

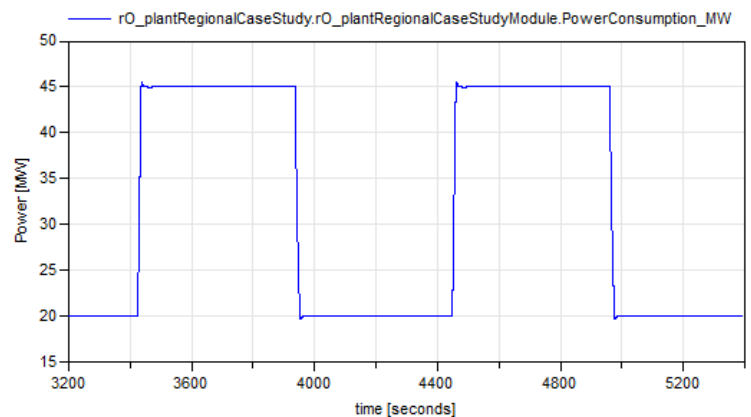

Figure 28: Electric power consumed by desalination plant under renewable ramp rate of: (a) $0.21 \mathrm{MWe} / \mathrm{s}$; (b) $2.1 \mathrm{MWe} / \mathrm{s}$ (NHES_Arizona).

\subsubsection{Impact of renewable variability}

In this test, the renewable generation is characterized by a trapezoidal signal as shown in Figure 10, with a width of $500 \mathrm{~s}$, two ramp rates of 0.21 and $2.1 \mathrm{MWe} / \mathrm{s}$ and amplitude of $25 \mathrm{MWe}$ such that the renewable penetration is $12 \%$. These ramp rates were selected after identifying that the maximum ramp rate observed on the actual solar power data collected was $0.35 \mathrm{MWe} / \mathrm{s}$ without power smoothing. It is also assumed a constant electrical generation to the electric grid of 180 MWe. Figure 28 shows the time series of the electric power consumed by the desalination plant in response to a time varying renewable generation. Increases in renewable variability are quickly matched by controlled increases in electrical load consumptions. Although not shown to free page space, it was observed that the turbine shaft speed is essentially unperturbed by rapidly requiring the RO plant to consume power generated by the PV solar plant for water desalination. These results suggest that the high variability of renewable energy can be effectively managed by NHES_Arizona, while maintaining adequate dynamic performance.

\subsubsection{Power smoothing for renewable variability attenuation}

In this test, the system performance is evaluated under several values of power smoothing provided by an electrical battery. assuming a constant electrical generation to the 


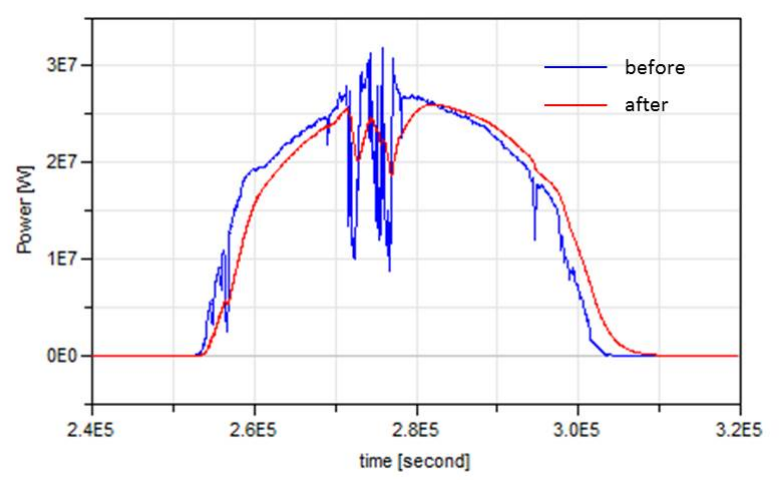

Figure 29: Renewable generation before and after power smoothing with a time constant of 1800s (NHES_Arizona).

electric grid of 165 MWe and an actual Arizona PV solar profile with six PV units. Figure 29 shows the renewable generation profiles before and after the power smoothing effect introduced by the electric battery for a power smoothing time constant of $1800 \mathrm{~s}$. For this figure, the instantaneous power output differences and the areas of continuous charge/discharge cycles correspond to the particular charge/discharge power and energy storage values accommodated by the electric battery. While the largest difference in the instantaneous power output corresponds to the minimum charge/discharge power required for the battery, the largest single contiguous area corresponds to its minimum required energy storage capacity. In this case, the battery needs to have a power rating of $21 \mathrm{MWe}$ and storage capacity of $13 \mathrm{MWe}-\mathrm{hr}$ to achieve the smoothing effect reported in Figure 29. As in the NHES case regarding Texas, the bigger the battery is, the more power smoothing can be achieved on the electrical power obtained from renewable generation. Since the capital and operational costs of the battery are directly related to its size, this test provides a benchmark when considering the trade off between the benefit of incorporating power smoothing to smooth the variability introduced by the renewable source versus the cost of installing system scale ESE.

\subsubsection{Ancillary service: Response time and ramp rate}

In order to assess the response time and ramp rate characteristics of NHES_Arizona, a demand profile with a step change as in Figure 11 is used, with a height of $10 \mathrm{MWe}$, duration of $0.001 \mathrm{~s}$, startValue of $155 \mathrm{MWe}$, and startTime of $2500 \mathrm{~s}$. A constant PV solar profile of $18 \mathrm{MWe}$ was also assumed. In particular, the transient is initiated at 2500 $\mathrm{s}$ via a $10 \mathrm{MWe}$ increase in electrical grid demand (from an initial generation level of 155 $\mathrm{MWe}$ ). This increase is completed within $0.001 \mathrm{~s}$ (hence a very high ramp rate). Figure 30 shows the time series for both the electrical and mechanical torques at the steam turbine shaft. As can be seen, it requires about 1 second for the mechanical torque to match the corresponding electrical torque, which in turn takes about four seconds to settle back to its original value; this transient delay depends on the particular dynamics imposed by the desalination plant. This fast response is likely due to effective control strategies implemented, but may also be attributed to the potential absence of engineered 


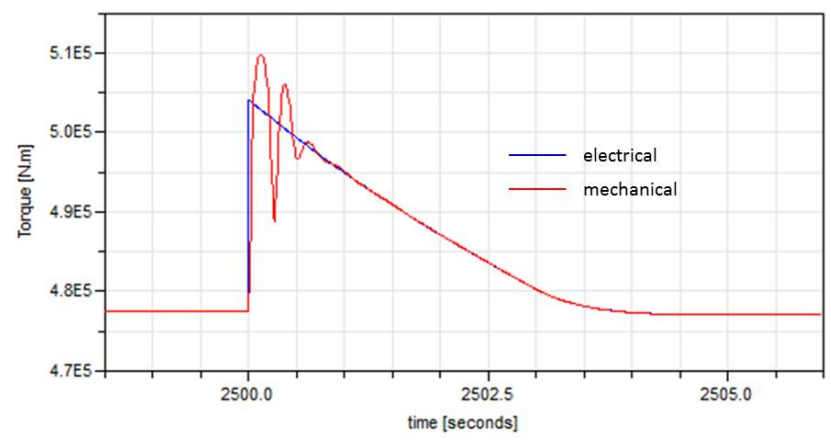

Figure 30: Electrical and mechanical torque at the steam turbine shaft (NHES_Arizona).

constraints (imposed for safety, for example) in the model that may more realistically characterize all key components of concern. Additional constraints will be implemented in future model refinement. Regardless, this result strongly suggests that NHES_Arizona can begin responding very quickly and change its response fast enough to participate in the electric grid ancillary services considered.

\subsubsection{Ancillary service: Load following}

As suggested by the previous test, NHES_Arizona is predicted to respond fast enough to participate in the ancillary services considered. This test is to further demonstrate the capability of NHES_Arizona for load following. An Arizona region actual profile is assumed for the electrical generation to the electric grid and a constant PV solar profile of 18 MWe. Figure 31 shows the time series of the temperature and steam flow at the outlet of the steam generator. Notice that changes in load demand do not lead to changes in these two process variables as these changes are essentially accommodated by the use of the flexible electrical load provided by the RO plant. This adaptation provided by the desalination plant can be observed in Figures 32 and 33. A decrease in the grid electrical demand must be compensated by demanding an increase on electricity consumption at the desalination plan, which is achieved by increasing fresh water production; furthermore, water purification increases with an increase in fresh water production; a similar logic applies regarding the opposite way. Notice from these figures that while the production and concentration of fresh water vary as the demand varies, the quality of the fresh water produced is well within water purity requirements (i.e., $500 \mathrm{mg} / \mathrm{kg}$ ) at all times. These results suggest that NHES_Arizona can act as a highly responsive device to meet load following needs by delivering the necessary electricity generation profile demanded by the electric grid, while correspondingly adjusting operations to maintain adequate operating conditions.

\subsubsection{Ancillary service: Operating reserve}

This test is to further demonstrate the operating reserve capacity that NHES_Arizona can provide to the electric grid. A demand profile with a step change as in Figure 11 is used, with a height of $10 \mathrm{MWe}$, duration of $600 \mathrm{~s}$, startValue of $155 \mathrm{MWe}$, and startTime 


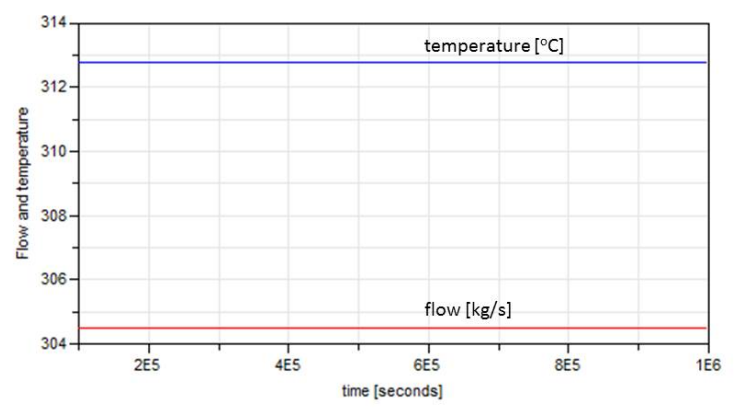

Figure 31: Outlet flow and temperature at steam generator (NHES_Arizona).

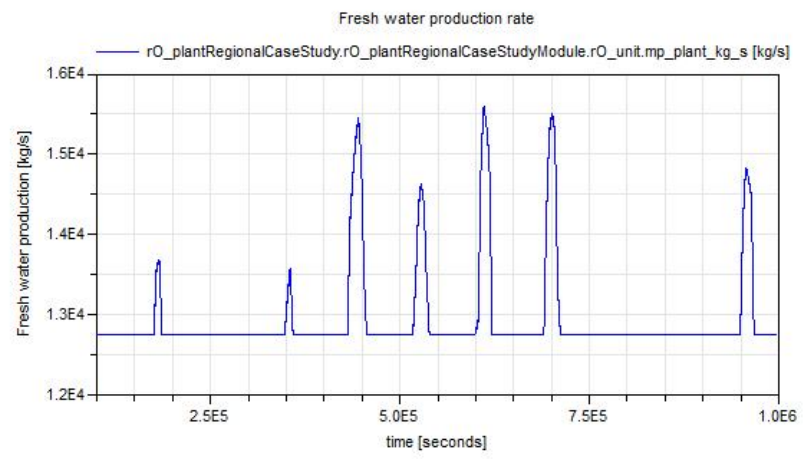

Figure 32: Fresh water production rate (NHES_Arizona).

of 2500 s. A constant PV solar profile of 18 MWe was also assumed. In particular, the requested electricity increases from 155 MWe at $2500 \mathrm{~s}$ to 165 MWe over 10 minutes, which corresponds to the particular ancillary service requirement for operating reserve. Figure 34 shows the time series for the power consumed by the desalination plant. As shown in this figure, the power supervisor quickly acts by demanding changes in the load to be consumed by the desalination plant to effectively accommodate the increased demand. Likewise, Figure 35 shows the time series for the pressure of the steam flow leaving the steam generator. The pressure response from time zero to $2500 \mathrm{~s}$ corresponds to the system initialization from cold shutdown to full operation. Notice the very small perturbation from $2500 \mathrm{~s}$ and beyond in the pressure caused by the indicated demand increase.

These results suggest that NHES_Arizona can provide a large spinning capacity. Being essentially in standby mode with respect to the electric grid, this configuration essentially exhibits zero startup and shutdown times to deliver the requested operating reserve services. This is achieved by the fact that NHES_Arizona offers more than one energy utilization avenue, allowing electricity to be diverted to the desalination plant to increase or decrease electricity delivered to the electric grid quickly when demanded. 


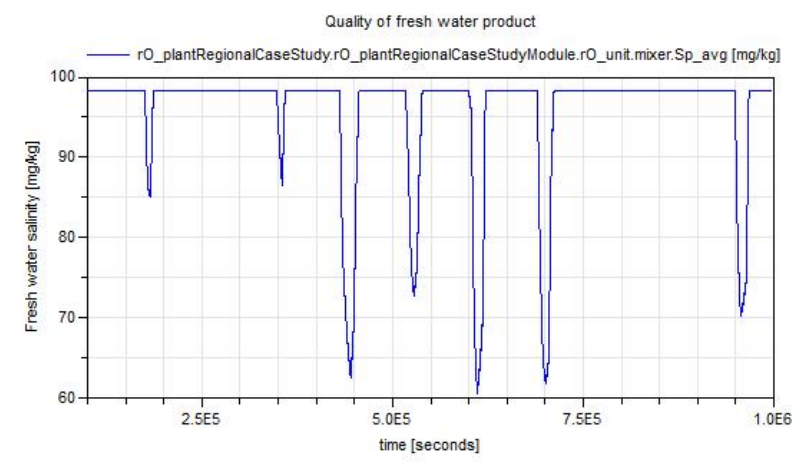

Figure 33: Quality of fresh water product (NHES_Arizona).

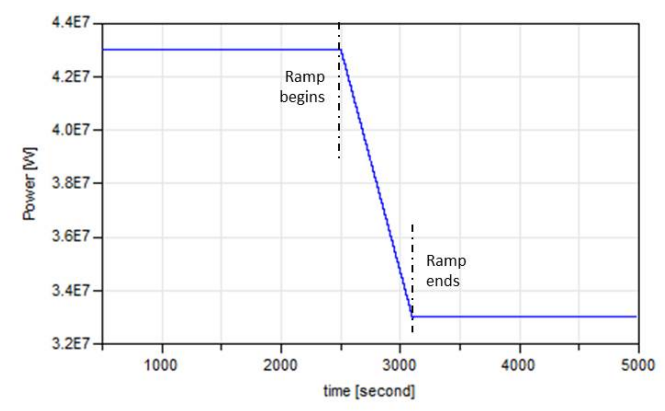

Figure 34: Power consumed by fresh water production plant (NHES_Arizona).

\section{CONCLUSIONS}

Dynamic analyses of two NHES configurations were carried out to understand various dynamic challenges and opportunities that may arise from accommodating increasing levels of renewable penetration. The selected NHES configurations include components producing electricity and variable energy generation and utilization components to yield multiple energy commodities, including chemical (e.g., gasoline) and basic (e.g., fresh water) products. Such advanced configurations enable flexible energy and power management, addressing the high variability arising from integrating renewable energy and modern loads into the electric grid. The results lead to the following findings:

- NHES can be designed in numerous configurations to meet diverse technical specifications, and possibly accommodating various business and financial models.

- NHES can lead to energy use optimization and carbon use reduction for the combined commodity, electric grid, and industrial manufacturing sectors.

- NHES enable flexible operations to support FOM optimization, uncertainty planning, and real time energy management. 


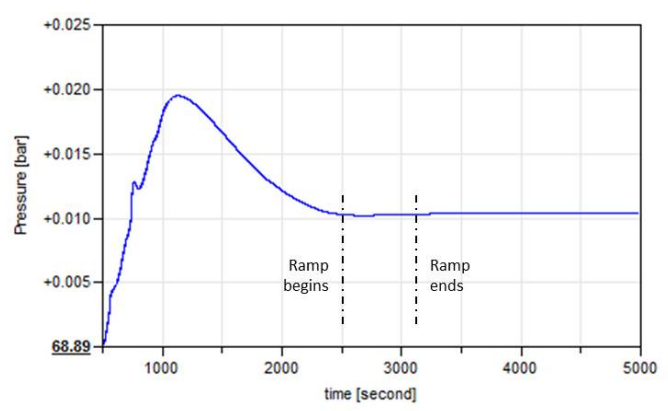

Figure 35: Pressure at steam generator outlet flow (NHES_Arizona).

- Technical and economic FOM may drive the design and operations optimization of NHES.

- NHES production of electricity and additional commodities can be controlled to yield maximum economic value, considering operational costs, feedstock costs, and commodity pricing.

- NHES can address high penetration, variability, and uncertainty levels in variable energy resources, which are challenging to accommodate using traditional energy systems that produce electricity only.

- For example, the results here reported show that NHES_Texas can accept levels of renewable penetration and ramp rates greater than $20 \%$ and $0.3 \mathrm{MWe} / \mathrm{s}$, respectively, with these values being $14 \%$ and $2.1 \mathrm{MWe} / \mathrm{s}$ for NHES_Arizona. Additional analysis is needed to determine operational limits within defined safety constraints.

- NHES can provide operating reserves to stabilize the electric grid while maintaining the electric grid inertia even with increased renewables penetration, thus supporting more robust transient grid response and addressing the anticipated near term power production transitions in the U.S.

- NHES can be operated as dispatchable flexible energy resources to address variability and uncertainty challenges within the electric grid by rapidly changing electricity outputs. As opposed to single output generators that may need to operate in load following, NHES units could maintain baseload generation by diverting energy to produce alternative commodities at times of reduced grid demand.

- By having an alternative path for energy conversion, NHES avoid operation at a minimum operating point where units tend to be less efficient. NHES can also be viewed as always in standby, exhibiting zero start up/shut down times from the electric grid perspective.

- NHES can flexibly provide grid services over various time horizons.

- NHES can participate in most ancillary service markets, while providing additional economic benefits through the sale of alternative products. 
- NHES_Texas and NHES_Arizona can initiate to change their energy distribution quickly following a change in the required electricity generation and settle on the order of seconds based on the current model fidelity.

- NHES can increase or decrease its electricity generation over a large range and maintain the change for long time periods.

- NHES_Texas and NHES_Arizona have a capacity of 45 MWe and 30 MWe, respectively, for participation in operating reserve services. Typically limited by the rated capacity of their associated FLR, higher operating reserve capacity values can be achieved by expanding their existing FLR and/or installing additional FLR, such as a hydrogen generation plant.

- NHES can significantly reduce $\mathrm{CO}_{2}$ emissions through the use of a nuclear baseload unit and renewables to meet grid demand and the thermal and electrical needs of industrial plants.

- For the selected NHES, an annual reduction of 1.4 million metric tons in $\mathrm{CO}_{2}$ emission(or equivalently, about $0.9 \mathrm{~kg}$ of $\mathrm{CO}_{2}$ per $\mathrm{kWh}$ ) is achieved by using a SMR as the baseload unit as opposed to using a NG fired baseload unit.

- Recall that there is no $\mathrm{CO}_{2}$ production in NHES_Arizona. On the other hand, $\mathrm{CO}_{2}$ production in NHES_Texas varies accordingly with changes in net load. For example, 0.35 million metric tons in $\mathrm{CO}_{2}$ annual emission is produced when the wind farm delivers $85 \mathrm{GWhr}$ under a constant grid demand of $171 \mathrm{MW}$. This $\mathrm{CO}_{2}$ emission value would decrease if the renewable energy generation increases and viceversa.

As mentioned in the introduction, simulation results were not validated against measurements collected from real industrial processes. This activity is planned for future efforts. While the intermittent and stochastic nature of renewable energy generation was included in the renewable generation profiles utilized, the models developed do not currently contain either probabilistic modeling constructs characterizing stochastic processes and other sources of uncertainty typically encountered in actual installations. Future efforts also include conducting error analysis after uncertainty mechanisms are incorporated in the simulation models and results.

\section{Acknowledgment}

This work is supported by the Energy Security Initiative (ESI) and the Advanced Reactor Technologies (ART) Program at Idaho National Laboratory under the U.S. Department of Energy Contract DEAC0705ID14517.

\section{References}

[1] Department of Energy, Report on the first quadrennial technology review, Tech. rep., Department of Energy (Sep, 2011).

[2] N. Hamsic, A. Schmelter, A. Mohd, E. Ortjohann, E. Schultze, A. Tuckey, J. Zimmermann, Increasing renewable energy penetration in isolated grids using a flywheel energy storage system, in: International Conference on Power Engineering, Energy and Electrical Drives, 2007, pp. 195 -200. 
[3] E. Hittinger, J. Whitacre, J. Apt, Compensating for wind variability using co-located natural gas generation and energy storage, Energy Systems 1 (2010) 417-439.

[4] S. Aumeier, R. Cherry, R. Boardman, J. Smith, Nuclear hybrid energy systems: Imperatives, prospects, and challenges, in: 2nd International Conference on Asian Nuclear Prospect, Nagoya, Japan, 2010.

[5] H. E. Garcia, A. Mohanty, W. Lin, R. Cherry, Dynamic analysis of hybrid energy systems under flexible operation and variable renewable generation - part i: Dynamic performance analysis, Energy 52 (2013) $1-16$.

[6] H. E. Garcia, A. Mohanty, W. Lin, R. Cherry, Dynamic analysis of hybrid energy systems under flexible operation and variable renewable generation - part ii: Dynamic cost analysis, Energy 52 (2013) $17-26$

[7] S. Bragg-Sitton, R. Boardman, M. Ruth, O. Zinaman, Integrated nuclear-renewable energy systems: Foundational workshop report, Tech. rep., Idaho National Laboratory, INL/EXT-14-32857 (Aug. 2014).

[8] D. Brück, H. Elmqvist, S. E. Mattsson, H. Olsson, Dymola for multi-engineering modeling and simulation, in: Proc. 2nd International Modelica Conference, Oberpfaffenhofen, Germany, March 18-19, 2002.

[9] J. S. Kim, J. Chen, H. E. Garcia, Modeling, control, and dynamic performance analysis of a reverse osmosis desalination plant integrated within hybrid energy systems, EnergySubmitted, under review.

[10] Lee, Texas his new peak output, U.S. Energy Information Adminstration: Today in Energy: http://www.eia.gov/todayinenergy/detail.cfm?id=16811 Retrieved on January 10, 2015.

[11] McFarland, Twelve states produced $80 \%$ of u.s. wind power in 2013, U.S. Energy Information Adminstration: Today in Energy: http://www.eia.gov/todayinenergy/detail.cfm?id=15851 Retrieved on January 10, 2015.

[12] U.S. Energy Information Adminstration, Crude oil production, Petroleum \& Other Liquids: http://www.eia.gov/dnav/pet/pet_crd_crpdn_adc_mbblpd_a.htm Retrieved on February 10, 2015.

[13] U.S. Energy Information Adminstration, Natural gas gross withdrawals and production, Natural Gas: http://www.eia.gov/dnav/ng/ng_prod_sum_a_EPG0_VGM_mmcf_a.htm Retrieved on February 10,2015

[14] Texas Administrative Code, Title 16; Part 1; Chapter 16; Rule 3.32

[15] B. T. Ewing, M. C. Waston, T. McInturff, D. Liang, Current and future economic impacts of the texas oil and gas pipeline industry, Tech. rep., Lubbock, TX: Texas Tech Univeristy (2014).

[16] R. A. Wood, R. D. Boardman, M. W. Patterson, Nuclear-integrated methanol-to-gasoline production analysis, Tech. rep., Idaho Falls, ID: Idaho National Laboratory, TEV-667 (2010).

[17] power-technology, Top 10 biggest wind farms, power-technology.com: http://www.powertechnology.com/features/feature-biggest-wind-farms-in-the-world-texas/ Retrieved on February 18, 2015.

[18] Cielo Wind Power, Wildorado wind ranch, Cielo Wind: http://www.cielowind.com/projects/completeddevelopments/wildorado-wind-ranc Retrieved on February 18, 2015.

[19] J. Chen, H. E. Garcia, J. S. Kim, S. M. Bragg-Sitton, Operations optimization of nuclear hybrid energy systems, IEEE Trans. Sustainable EnergySubmitted, under review.

[20] Arizona Public Service, 2014 integrated resource plan, Phoenix: Arizona Public Service.

[21] Arizona Department of Water Resources, Arizona's next century: A strategic vision for water supply sustainability, Phoenix: Arizona Department of Water Resources.

[22] L. B. Brug, emPOWER ARIZONA: Executive Energy Assessment and Pathways 2014, Phoenix: Arizona Govenor's Office of Energy Policy.

[23] B. J. Kirby, Spinning reserve from responsive loads, Tech. rep., Oak Ridge, TN: Oak Ridge National Laboratory (2003).

[24] Spinning reserve and non-spinning reserve, Tech. rep., California ISO (January 31, 2006).

[25] B. J. Kirby, Demand response for power system reliability: FAQ, Tech. rep., Oak Ridge, TN: Oak Ridge National Laboratory, ORNL/TM-2006/565 (Dec. 2006).

[26] M. Lei, L. Shiyan, J. Chuanwen, L. Hongling, Z. Yan, A review on the forecasting of wind speed and generated power, Renewable and Sustainable Energy Reviews 13 (4) (2009) 915 - 920.

[27] Making use of TMY data, PVEducation.org.

[28] A. P. Dobos, PVWatts version 5 manual, Tech. rep., National Renewable Energy Laboratory, NREL/TP-6A20-6241 (Sep. 2014).

[29] C. R. Landau, Optimum tilt of solar panels, http://www.solarpaneltilt.com/,.

[30] Solar radiation on a tilted surface, PVEducation.org. 
[31] R. Perez, P. Ineichen, R. Seals, J. Michalsky, R. Stewart, Modeling daylight availability and irradiance components from direct and global irradiance, Solar energy 44 (5) (1990) 271-289.

[32] E. Skoplaki, J. Palyvos, On the temperature dependence of photovoltaic module electrical performance: A review of efficiency/power correlations, Solar energy 83 (5) (2009) 614-624.

[33] J. Jie, Y. Hua, H. Wei, P. Gang, L. Jianping, J. Bin, Modeling of a novel trombe wall with PV cells, Building and Environment 42 (3) (2007) 1544-1552. 